\title{
Alkaloids in Contemporary Drug Discovery to Meet Global Disease Needs
}

\author{
Sharna-kay Daley ${ }^{1}$ and Geoffrey A. Cordell ${ }^{1,2, * \mathbb{D}}$ \\ 1 Natural Products Inc., Evanston, IL 60202, USA; sharnakaydaley@yahoo.com \\ 2 Department of Pharmaceutics, College of Pharmacy, University of Florida, Gainesville, FL 32610, USA \\ * Correspondence: pharmacog@gmail.com
}

Citation: Daley, S.-k.; Cordell, G.A. Alkaloids in Contemporary Drug Discovery to Meet Global Disease Needs. Molecules 2021, 26, 3800. https://doi.org/10.3390/ molecules 26133800

\section{Academic Editors: Maria José}

Umbelino Ferreira and Juan

Francisco Leon

Received: 12 April 2021

Accepted: 14 June 2021

Published: 22 June 2021

Publisher's Note: MDPI stays neutral with regard to jurisdictional claims in published maps and institutional affiliations.

Copyright: (c) 2021 by the authors. Licensee MDPI, Basel, Switzerland. This article is an open access article distributed under the terms and conditions of the Creative Commons Attribution (CC BY) license (https:/ / creativecommons.org/licenses/by/ $4.0 /)$.

\begin{abstract}
An overview is presented of the well-established role of alkaloids in drug discovery, the application of more sustainable chemicals, and biological approaches, and the implementation of information systems to address the current challenges faced in meeting global disease needs. The necessity for a new international paradigm for natural product discovery and development for the treatment of multidrug resistant organisms, and rare and neglected tropical diseases in the era of the Fourth Industrial Revolution and the Quintuple Helix is discussed.
\end{abstract}

Keywords: alkaloids; drug discovery; fourth industrial revolution; quintuple helix; neglected tropical diseases; multidrug resistance; genomics; artificial intelligence

\section{Introduction}

\subsection{Alkaloids, Drug Discovery, and the Fourth Industrial Revolution}

Alkaloids are a paradox and an enigma. Inexplicable, contradictory, mysterious, and yet essential for all forms of life. There are the alkaloids we love as spices (capsaicin, piperine, and the Murraya alkaloids), those we fear as toxins (batrachotoxin, strychnine, and aconitine), those which affect perceptions in the brain (psilocin, $N, N$-dimethyltryptamine, and ibogaine), and there is caffeine, the global stimulant of coffee, tea, maté, and guarana. There are those alkaloids which can relieve pain and, in another context, elicit pain and enormous disruption in society (morphine and cocaine), and alkaloids whose diverse impacts can strain health care systems (nicotine). There is also a plethora of alkaloids from diverse sources which serve as medicines (paclitaxel, vincristine, the cephalosporins, the penicillins, atropine, pilocarpine, quinine, vincamine, etc.). A recent review has provided a concise introduction to plant alkaloids and their broad biological impact on human health [1], and some of the biosynthetic aspects of alkaloids have been summarized [2].

There have been several excellent reports of the role of natural products in drug discovery and the challenges to be faced [3-11]. The terrestrial and marine biomes are recognized as essential providers of new source opportunities for natural product discovery [12-15]. This review will examine the need for new medicinal agents, the evolving strategies for natural product drug discovery, and how the various facets of the Fourth Industrial Revolution (4IR) [16,17], interfacing with the activities embodied in the Quintuple Helix [18,19], provide new opportunities for the development of natural products [20]. The focus will be on the role of alkaloids in the complex milieu of the evolving discovery process, particularly for overcoming multiple drug resistance (MDR), and for the treatment of rare and tropical diseases, including the neglected tropical diseases (NTDs). It will approach the question of how the present and future levels of technological development in the 4IR can enhance the utilization of alkaloids as drugs in new ways to address these global health needs and the welfare of the patient. What are the paradigms in the strategies of the discovery programs that need to change for alkaloids as drugs to be sustainable [21]? 


\subsection{Global Disease Burden and the Need for New Drugs}

In a rational world, the priorities for drug discovery would examine the medicinal agent options, and then mirror the existing and projected disease burdens of humankind; they do not. Most of the world has no say whatsoever in how disease priorities are addressed in terms of dedicated drug discovery. The nature of the communicable and non-communicable diseases of humankind, their changing demographics, the causes of mortality and the forecasting of needs, are all aspects of the Global Burden of Disease (GBD) data analysis, an ongoing project of the World Health Organization, the World Bank, and the Harvard School of Public Health since 1992 [22]. In October 2020, The Lancet editorial in a Special Issue dedicated to the 2019 GBD stated: "It's time for the global health community to change direction" [23]. The conclusion was reached as the present system of addressing the health care needs of the majority population of the world in terms of drug discovery are not being met [24-29]. There is an urgent need for natural and synthetic compounds to be available for biological assessment to address these medicinal agent needs. One of the major natural resources to be examined for drug discovery and development are the alkaloids.

\section{Introduction to Alkaloids}

\subsection{Background and Origins}

In 1805, the first alkaloid to be isolated in crude form, morphine, was reported by Sertürner; from opium, it remains an important medicinal agent [30]. A few years thereafter, the important antimalarial agent quinine was obtained [31]. Now it is realized that alkaloids are everywhere in the biome; in addition to plants and various microorganisms, terrestrial isolations have been reported from reptiles, amphibians, insects, mammals, and birds, as well as a diversity of marine sources including sponges, tunicates, corals, and microorganisms [32].

Currently, at least 60 plant-derived alkaloids are approved as drugs in various countries, together with numerous antibiotics and some compounds from marine sources [33]. Their biosynthetic origin is from L-amino acids (tryptophan, ornithine, lysine, phenylalanine, proline, glutamine, histidine, etc.), with attachments from terpenoid biosynthesis, polyketide biosynthesis, and the shikimate pathway producing a wide range of heterocyclic nuclei [32]. In some alkaloids the nitrogen atom is introduced into a preformed nucleus (e.g., terpenoid alkaloids). These pathway relationships and the breadth and depth of the metabolic pool are being actively pursued [34-40]. As biologically significant metabolites, alkaloids are often highly potent, and in some instances exclusive in their mode of action and application [2]. New alkaloids with a broad range of contemporary biological activities continue to be isolated and characterized. In 2020 alone, the Journal of Natural Products reported 316 new alkaloids with 124 metabolites displaying 25 different biological activities.

About twenty years ago, a discussion of alkaloids in drug discovery focused on the chemotaxonomy, biological testing, and future development of plant-derived alkaloids [33]. Two clear outcomes of that analysis related to the structural diversity and biological assessment of alkaloids. The first was that, of the 135,500 plant-derived natural products known at that time (2000), 21,120 alkaloids represented $15.6 \%$ of the structures, and $32.5 \%$ of the 5750 natural product scaffolds. On the other hand, only $3.3 \%$ of the alkaloids had more than five biological tests associated, and $76.4 \%$ of alkaloids had not been subjected to even a single bioassay [33]. An analysis of the 60 pure alkaloids used as pharmaceutical agents globally revealed that the average molecular weight (348.9), the number of $\mathrm{NH}$ and $\mathrm{OH}$ groups (0.97), and average number of $\mathrm{O}$ and $\mathrm{N}$ atoms (5.55) all fell within the parameters for a "drug-like" molecule [41,42]. In addition, looking at the profile of alkaloid occurrence in higher plants, about $14.2 \%$ of higher plants contain alkaloids, although 153 plant families (674 genera) had not been examined for alkaloids, and 50 plant families had three or fewer characterized alkaloids [33]. The twenty most important alkaloid-containing plant families are (alphabetically) the Amaryllidaceae, Annonaceae, Apocynaceae, Asteraceae, Berberidaceae, Boraginaceae, Buxaceae, Celastraceae, Fabaceae, Lauraceae, Liliaceae, Loganiaceae, 
Menispermaceae, Papaveraceae, Piperaceae, Poaceae, Ranunculaceae, Rubiaceae, Rutaceae, and Solanaceae. From a strategic perspective, these plant families may be regarded as targets, particularly to explore uninvestigated species used medicinally, or they may be strategically avoided for the fear of redundancy in isolation.

The microbial world is even more diverse and underexplored [43]. The number of bacterial species is estimated to be between 10 million and 1 billion [44], and of the soil bacteria only $0.3 \%$ are judged to have been cultured [45]; for the marine environment the number examined thus far is thought to be only $10^{-5} \%$. Of the estimated 1.1 million fungi which are considered to exist, around $100 \mathrm{~K}$ are named, and of the estimated $140 \mathrm{~K}$ mushrooms, about 14,000 are characterized [46]. Thirty-one bacterial phyla of the 61 known remain to be cultured and studied through metabolomics [47]. In the microbial world of fungi and bacteria Streptomycetes and Actinomycetes are rich sources, and beyond these families the opportunities for new compound discovery from natural, potentially sustainable, sources are truly vast.

\subsection{The Sourcing of Alkaloids}

Where, what, and how to source alkaloids are primary questions for any natural product drug discovery program. That source may be a specialized marine or terrestrial location, from a microbe, an extract or compound library based on traditional medicine reports, a specific taxonomic source, or through in silico binding studies of alkaloid libraries at the active sites of specific enzymes or receptors (vide infra). In the past twenty-five years cyanobacteria have become a significant source of new alkaloid metabolites possessing a range of biological activities [48,49].

Generating and maintaining a meaningful number of pure alkaloids for bioassay, even for a modest in vitro screening program, is a significant challenge. Some alkaloids can be purchased, but source collection and re-isolation would be necessary to truly populate library space. Relief may come from concentrates of alkaloid fractions, but even this approach leads to relatively small (1000-2000) sample numbers. Maintaining the stability of alkaloids, particularly basic alkaloids, requires low temperature storage in an inert atmosphere to avoid transformation to their $\mathrm{N}$-oxides. For such alkaloid-based drug discovery to be successful, a different strategy is necessary, requiring centralization of analyzed samples, including semi-purified alkaloid concentrates, and a distribution network for biological testing.

Plants are hosts to both fungi and bacteria which have the capacity for independent metabolite production [50,51]. A recent review summarized the isolation or detection of selected alkaloids known to be biologically active from a widely sourced range of endophytic fungi [52]. Of greater interest from a drug discovery perspective was the range of alkaloids, frequently representing completely new scaffolds, characterized from endophytic fungi in the period 2007-2020 [52]. Many of the isolates were examined only for their cytotoxic or antimicrobial activity, providing a discovery opportunity for in silico and possibly subsequent in vitro evaluation.

\subsection{Alkaloids in Drug Discovery for Tropical and Neglected Diseases}

NTD diseases such as African trypanosomiasis, Chagas' disease, leishmaniasis, schistosomiasis (bilharzia), filariasis, onchocerciasis, trachoma, and leprosy, are conducted by specific parasites, helminths, and bacteria. These NTDs cause major human suffering in at least 149 countries in the world resulting in over 500,000 deaths and affecting about 1.5 billion people, including 900 million children, and have devastating effects on economies, productivity, education, healthcare systems, and nutrition, as well as producing long-term disabilities [53]. They represent the antithesis of a healthy planet/healthy people goal for sustainable development [54].

The Access to Medicine Index 2021 report offers a detailed analysis of the efforts of 20 leading pharmaceutical companies to provide access to critical medicines (mostly NTDs) for low- and middle-income countries who represent $83 \%$ of the global population [55]. For 
the 16 emerging infectious diseases, the 20 major companies had no development pipeline for 10 of them, leaving the majority of those in need without drug resources. A detailed survey of the status of natural products and their derivatives in the drug approval process globally [56] indicated that, between 1981 and 2019, 363 (30\%) of the 1205 small molecule new chemical entities that were approved for clinical use were natural products, natural product derivatives, or botanicals. Eighteen compounds were approved for antiparasitic use in the time frame, reflecting $1.5 \%$ approvals for drugs globally over 39 years. Nine of these approvals were for natural products or natural product derivatives, six for malaria, two for onchocerciasis, and one for trypanosomiasis, corresponding to $0.25 \%$ approvals for NTDs [56].

In January 2021, the World Health Organization introduced a second roadmap for the twenty identified [57] NTDs "Ending the Neglect to Attain Sustainable Development Goals" [58]. Surprisingly, in a "gap" assessment, there was no consideration given to the effectiveness and toxicity of the available drugs for NTDs, and no discussion of the need for drug discovery for the 19 infectious diseases. Importantly, except for ivermectin, the drugs being distributed by the donor pharmaceutical company partners are typically the "old-timer" drugs (e.g., melarsoprol, albendazole, and nifurtimox) [53], with their attendant clinical failings [59]. Establishing mechanisms for innovation and the creation of new drugs was not discussed. These mechanisms are much needed given the current situations with NTDs such as bilharzia, lymphatic filariasis (elephantiasis), and leishmaniasis, the details of which are discussed below.

Bilharzia - Fresh water snails release the cecaria of flat worms of the genus Schistosoma (S. monsonii, S. japonicum, and S. haematobium), and are responsible for the disease bilharzia, also known as schistosomiasis, which is second only malaria in terms of morbidity from parasitic diseases [60]. Disease outcomes are not usually detected until overt complications are diagnosed [61,62]. Praziquantel has been the anthelmintic drug of choice for the past 40 years $[63,64]$, although it is not effective against newly developed worms, and cannot prevent re-infection; there are also concerns regarding resistance [65-67]. Epiisopilotulorine (1) from the leaves of Pilocarpus microphyllus Stapf. ex Wardlew (Rutaceae) showed very modest activity in vitro and in vivo [68]. More promising is piplartine (2) from Piper tuberculatum Jacq. (Piperaceae) among other Piper species $[69,70]$. It showed good activity at $6.3 \mu \mathrm{M}$ against the egg-laying, was lethal to the worms at $12.6 \mu \mathrm{M}$ [71], and had a good SI [72]. It also acted synergistically with dermaseptin against S. mansoni [73], although bioavailability was modest [74-76]. This is an important hit to be pursued given the level of activity and safety, and that it originates from a sustainable source. More targeted, delivery-focused research, aimed at enhancing the pharmacokinetic profile, is warranted.

Lymphatic filariasis is caused by the filarial worms Brugia malayi, B. timori, and Wuchereria bancrofti [77], and WHO estimates that almost 950 million persons in 54 countries are presently infected, mostly in Africa [53]. Ivermectin is the current drug of choice in combination with diethylcarbamazine, and albendazole, but they are not effective against the adult worm, only the microfilarial stages of the parasite [78]. The most promising alkaloid is the steroidal glycoside solamargine (3) from the fruits of Solanum khasianum C.B. Clarke (Solanaceae) which was $100 \%$ lethal to the worms at $4 \mathrm{mg} / \mathrm{mL}$ (Figure 1) [77]. Some efforts to enhance availability through semi-synthesis, and provide analogs to explore the activity profile, have been reported [79]. 
<smiles>Cn1cnc(C[C@H]2COC(=O)[C@H]2C(O)c2ccccc2)c1</smiles>

epiisopilotulorine (1)<smiles>COc1cc(/C=C/C(=O)N2CCC=CC2=O)cc(OC)c1OC</smiles>

piplartine (2)

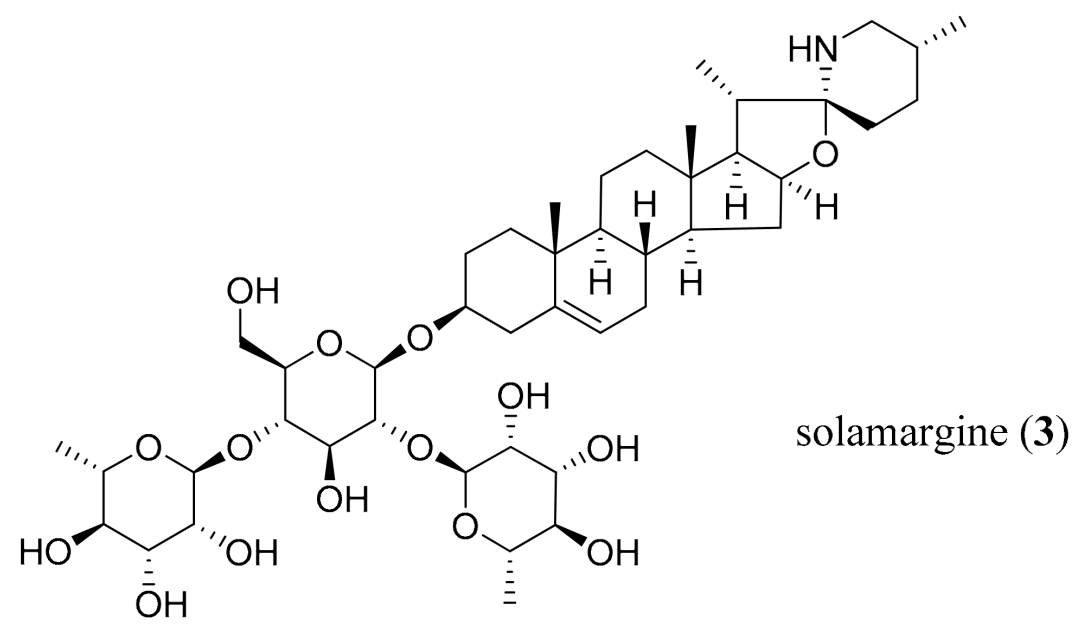

Figure 1. Alkaloids with anthelmintic properties.

Leishmaniasis, caused by the Leishmania parasite, is transmitted by females of over 90 sandfly species. There are three main forms cutaneous leishmania (CL) caused by $L$. major and L. tropica in the old world, and L. braziliensis and L. mexicana in the Americas [80]; mucotaneous leishmania (MCL) caused by L. braziliensis [81]; and visceral leishmaniasis (VL) produced by L. donovani in Africa and parts of Asia, and L. infantum for infection in North Africa, Europe, and Latin America. Left untreated, VL is 95\% lethal, and WHO estimates between $200 \mathrm{~K}$ and $400 \mathrm{~K}$ cases per year, mostly in Brazil, Ethiopia, India, and the Horn of Africa [53]. There are approximately 1 million cases of CL each year, mostly in Brazil, Algeria, Afghanistan, Iran, Syria, and Colombia [53]. MCL is prevalent in Peru, Brazil, and Bolivia [53]. Pentavalent antimonials, such as pentostam, remain the drug of choice [82], even though severe side effects include the destruction of veins and pancreatitis. Pentostam has been available since the 1940s, and although second-line drugs, such as amphotericin B, miltefosine, paromomycin, and sitamaquine are available, profound side effects are observed, as well as drug resistance. From these few examples, the need to bring a heightened focus to the global NTD burden [83], and to multiple drug resistance (MDR) in infectious diseases, with their tremendous human costs $[84,85]$, clearly remains.

\subsection{Antibiotic Drug Discovery}

The need for new classes of antibiotics for fungal and bacterial pathogens that are panresistant to the current drugs is dire and well-documented [56,86-90]. Overall, infectious disease is the second leading killer in the world, and the third in developed nations [91], with 17 million patients per year dying of bacterial infections [92]. The WHO has designated the ESKAPE pathogens (Enterococcus faecium, Staphylococcus aureus, Klebsiella pneumoniae, Acinetobacter baumannii, Pseudomonas aeruginosa, and Enterobacter spp.) [93], which kill over $700 \mathrm{~K}$ patients a year, as being of particular concern [94]. The Centers for Disease Control and Prevention in the US have listed 18 drug-resistant pathogens requiring attention in their latest report, of which five are categorized as urgent [95]. Unfortunately, even when small pharmaceutical companies are successful in developing a drug, such as plazomicin (4) by Achoagen, the post-approval financial (sales of $\$ 80$ million) and regulatory challenges 
may be too large a burden for economic survival. This represents a grave situation for global health care scientifically and financially, which needs to be addressed with great urgency [86].

The major issue in antibiotic drug discovery lies in the consistent emergence of antibiotic resistant strains of microbes due to the production of virulent genes encoding protective mechanisms. These include biofilm formation, beta lactamases, etc. Mitigation of the progression of antibiotic resistance includes more controlled use and stewardship of use, while maintaining access in middle- and low-income countries, coupled with improved local diagnostic testing to target more succinctly an effective antibiotic therapy for the individual patient [86]. In addition to controlling more aggressively the use of 30 different antibiotics [96] as animal and plant growth promoters [97], chemically based strategies to overcome drug resistance include: (i) seeking new antibiotic scaffolds through in-field or bioinformatics approaches, (ii) combining antibiotics in therapy, (iii) using adjuvants in combination or alternately for treatment, and (iv) structure modifications of existing antibiotics [43].

One of the classic examples to circumvent ineffective $\beta$-lactam therapy is the use of clavulanic acid (5) as an inhibitor of $\beta$-lactamases for therapy using cephalosporins [98]. Other alkaloids which can conduct these modulations include the phenothiazines [99-101]. Berberine (6), a well-established antimicrobial agent [102-105], inhibits biofilm formation of drug-resistant E. coli through the downregulation of quorum-sensing related genes [106]. It is available in good yield from several sources, including Berberis vulgaris L. (Berberidaceae), Coptis chinensis Franch. (Ranunculaceae), and Hydrastis canadensis L. (Ranunculaceae). Berberine (6) showed an additive effect with ampicillin in vitro against MRSA, and a synergistic effect with oxacillin [107]; activity against inflammatory bowel syndrome (IBD) was recently discussed [108]. The effectiveness of berberine (6) in treating diarrhea in adults and children in 38 controlled clinical trials in China [109], prompted synthetic analog development [110]. Berberine (6) shows strong inhibitory activity against the sortase of $S$. aureus [111]. Sortases are Gram-positive membrane-bound cysteine transpeptidases, and control multiple virulence mechanisms [112]. It is therefore a sustainably sourced alkaloid, already a commercial entity, and a prime candidate for repurposing.

Other alkaloids to be considered include sanguinarine (7) and pyranonigrin F (8). Sanguinarine (7), from Sanguinaria canadensis L. (Papaveraceae) and Macleaya cordata (Willd.) R.Br. (Papaveraceae), has shown both anticancer [113] and antimicrobial [114] activity, and was formerly used for its antiplaque activity in mouth washes, where it exhibits anti-Candida biofilm and anti-gingivitis activity $[115,116]$. Sanguinarine (7) exhibits potent activity against the ichthyotoxic, parasitic ciliate Ichthyophthirius multifiliis in carp [117], activity against phytopathogenic fungi [118], and potent effects on Schistosoma mansoni in vitro [119]. Pyranonigrin F (8) was isolated from the mangrove-associated endophytic fungus Penicillium brocae MA-231 [120]. It showed more potent activity than controls against S. aureus and the Gram - ve bacteria Vibrio harveyi and V. parahemolyticus, and antifungal activity against Alternaria brassicae and Colletotrichum gloeosprioides, Previously isolated antimicrobial alkaloids from marine sources include ascididemin (9) from the ascidian Cystodytes dellechiajei [121], eudistomin Y4 (10) from the ascidian Synoicum sp. [122], and the sterol sulfate derivative squalamine (11), bearing a spermidine moiety attached at C-3, from the dogfish shark Squalus acanthias L. (Squalidae) (Figure 2) [123,124]. 


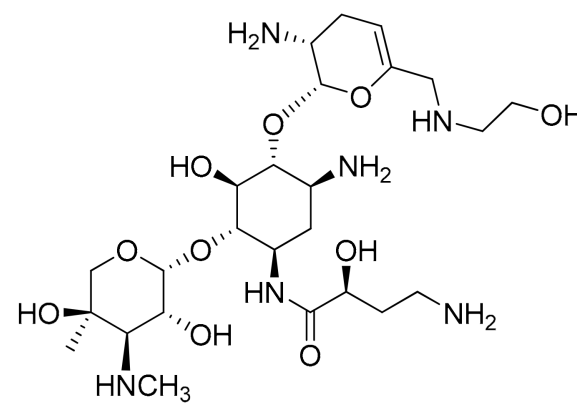

plazomicin (4)<smiles>C[n+]1cc2c3c(ccc2c2ccc4cc5c(cc4c21)OCO5)OCO3</smiles>

sanguinarine (7)<smiles></smiles>

clavulanic acid (5)<smiles>COc1ccc2cc3[n+](cc2c1OC)CCc1cc2c(cc1-3)OCO2</smiles>

berberine (6)<smiles>CCC/C=C/c1oc2c(c(=O)c1O)C(=O)N[C@H]2O</smiles>

pyranonigrin $\mathrm{F}(\mathbf{8})$<smiles></smiles>

ascididemin (9)<smiles>O=C(c1ccc(O)c(Br)c1)c1nccc2c1[nH]c1ccc(Br)cc12</smiles>

eudistamin Y4 (10)

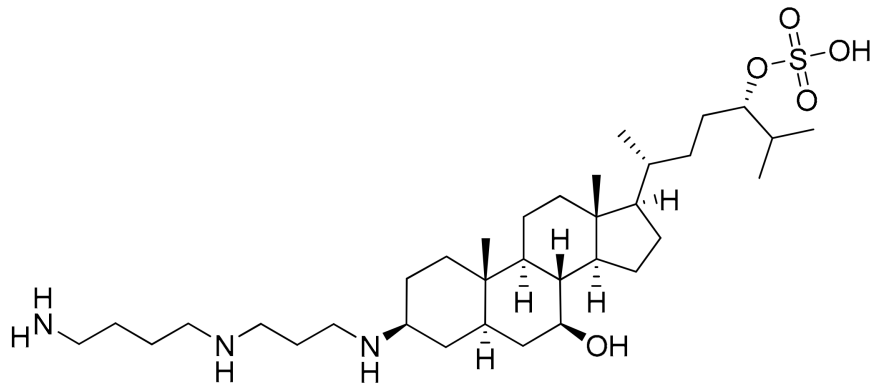

squalamine (11)

Figure 2. Alkaloids with promising antibacterial properties.

\subsection{Constraints for Alkaloids in Drug Discovery}

The absence of established pipelines in Big Pharma for alkaloids to overcome antibiotic drug resistance, and for the development of medicinal agents for rare and neglected tropical diseases, malaria, and tuberculosis, represents a significant time gap in the translation of a compound from in vitro active "hit" to clinical assessment. In addition, there are several significant experimental constraints which impede efforts of alkaloid drug discovery. The inclusion of a selectivity index was mentioned previously; other constraints include declining biological resources, the feasibility of testing, dereplication for known and bioassay-interfering compounds, and residual complexity.

Regarding declining resources, the diminishing supply of unexplored natural resources, due to deforestation in some of the most biodiverse countries, is not conducive to natural product drug discovery initiatives, particularly when that occurs in low-income areas of the world and in vulnerable populations [125-127]. Biodiversity losses through overharvesting in the wild for traditional medicines impact local health care and obviate the discovery of bioactive compounds from those sources before they are examined scientifically; the eons old symbiotic relationship between humans and natural medicine is lost forever [128]. Sustainable supply based on the originating resource evolves as an essential consideration $[129,130]$ and becomes an acute issue when taking a natural product after it is declared a "hit", and then possibly a "lead", placing it in line for advanced biological, pharmacological, and toxicological evaluation.

On the feasibility of testing, the failure to test isolates often relates to the physical distance between chemistry and biology; isolation and characterization are in one location, collaborative testing facilities are elsewhere. A second aspect of failure to test is based on 
availability. Small scale isolation procedures (conserving solvent and chromatographic resources) typically lead to limited quantities for biological assessment in more than one or two assays after structure elucidation, and may abrogate confirmatory tests. In addition, if the isolate is from a complex matrix, it may be challenging to acquire milligram quantities of more than 6-8 metabolites. Molecular networking [131,132] provides a clearer picture of the parent masses present, the structural relationships within a class of potential isolates in the matrix, and their novelty.

Concerning dereplication, the most important aspect of bioactivity-directed fractionation is to avoid the repeated isolation of compounds known to be active in the respective assay. This issue was recognized by Pharma in the early days of antibiotic discovery, and chemical dereplication was a subsequent concern in industry when dealing with plantbased drug discovery [133]. As it minimizes wasted resources and time on dead-end active extracts, dereplication for known bioactives has evolved as an essential element in the early discovery phase of natural product extracts [134] and is greatly facilitated by the access to integrated isolation, bioactivity, and mass spectral datasets (vide infra) [135-138]. However, it is not sufficient to identify known active compounds in an extract. From a drug discovery perspective, that known active metabolite might not explain the total activity observed in the extract. Consequently, there is an important caveat; namely, it is essential to correlate the biological activity and the UPLC/MS metabolite profile in the same timeframe in order to search by mass for new bioactives directly in the extract through an integrated chemical-biological-database platform [139,140].

The global issue for many natural products' discovery programs, of misusing resources on isolating known bioactive metabolites in an extract, has a new angle; namely, that many widespread compounds respond positively in a broad range of bioassays. These are noted as pan assay interference compounds (PAINS) [141,142] and invalid metabolic panaceas (IMPS) [143]. From an artificial intelligence (AI) perspective, algorithms are needed to identify these compounds (more than one may be present) at an early stage in the analysis of extracts and in extract libraries to avoid their confusion as false positives with truly active metabolites. Fortunately, the alkaloids on the IMPS list are few (berberine, Taxol, tetrandrine, and capsaicin [143]), which may reflect limited distribution based on the taxonomy of other alkaloids and/or limited bioassay assessment. The wide distribution of Taxol in plant endophytes was recently summarized and requires monitoring in plant extracts for its cytotoxic effects [52]. The endophytic metabolites will be present at very low levels, which raises the issue of residual complexity.

Residual complexity becomes apparent when a very minor, undetected, component in a "pure" compound is responsible for the observed, potent activity. Two alkaloids serve as lead examples, sesbanine and sesbanimide [144,145], and rufomyazine and rufomycin [146]. There is also the attempt to trace the anti-TB activity of the highly purified, ubiquitous triterpene ursolic acid [147]. The highest levels of assessed purity still may not detect very low levels of a potent compound, and sometimes only through synthesis or isolation from a different source can that situation become apparent.

\section{Discovery Strategies}

\subsection{Improved Collaborative Approaches}

Extensive collaboration is the key to successful drug discovery programs. To address the absence of a discovery pipeline and the dearth of in-house pharmaceutical company initiatives for long-term and consistent drug discovery for neglected diseases [55], national, regional, and in some instances global leadership is urgently required to respond to the desperate clinical need [86,90]. After the existing partnerships for global initiatives for NTDs was examined [148], the identified health care chasm prompted the development of new collaborative relationships and initiatives [43,148-151]. Going forward, however, more support from local and regional governments and foundations, as well as venture capital investment for collaborative initiatives, will be essential. One approach is to incentivize innovation for antibiotic drug discovery between small pharmaceutical and 
biotechnology companies and academia, which would focus on new alkaloid scaffolds and their development [152]. In the present drug approval paradigm, large companies will also be needed to conduct the final clinical development phases under specific licensing agreements. Translational science initiatives [153] to re-examine past drugs "shelved" by pharmaceutical companies is another development pathway for industrial-academic collaboration [154]. In Europe, an Innovative Medicines Initiative has been supported by the EU and by several leading European pharmaceutical companies, including academic clinical investigators [155]. Some of the industry-academic collaborations for drug discovery that have evolved over time to address specific discovery needs, and examined the various approaches, have been described [156].

After the poor research record for new NTDs was highlighted [157], the Drugs for Neglected Diseases Initiative (DNDi) was cofounded by the Doctors Without Borders organization using some of their Nobel Peace Prize award [149,158]. Over the years, other global health initiatives have evolved, and one of the challenges has been potentiating the synergy and coherence between these various efforts [159]; a coordinating umbrella organization has been proposed [43]. In 2020, a detailed pipeline analysis of the results from these initiatives revealed 538 candidate drugs for 35 neglected diseases [160]. However, only 68 of these compounds had activity related to the WHO NTDs. It was anticipated that about 600 candidates would be needed for assessment to achieve new clinical entities for each of the 12 NTDs identified, at an overall cost of USD 9.6 billion. The global (43 countries) DND $i$ program has afforded six new treatments, 12 new molecular entities, and overseen 25 clinical trials at a cost of about USD 200 million [158]. The explanation for these relatively modest costs relates directly to the practice of "patenting for public health" rather than for exclusivity and profit. These are valuable and innovative programs which need input from diverse sets of natural products, including alkaloids, in the early aspects of discovery. These research initiatives, fostered and supported financially through either the respective government and/or philanthropic foundations, are an important development for all parties involved, will hopefully lead to reducing the gaps in the drug pipeline for rare and NTDs, and find new solutions to the antibiotic resistance crisis. The strong caveat must always be that any new antimicrobial which overcomes resistance is accessible (i.e., available and affordable) to the majority global population.

\subsection{Targeted Discovery Based on In Silico Binding}

In silico approaches which can selectively identify key compounds, especially alkaloids, without resorting to the massive in vitro screening of huge compound libraries are highly beneficial. They utilize minimal resources, avoid the wasteful time and effort associated with the isolation of pure metabolites, and allow for testing in vitro only candidates with a high probability for activity [129,130,161-163]. If an enzyme structure is available for an active site, and has the possibility for the design of inhibitors, then probing with the diversity of known alkaloid structures is a viable strategy to develop potential metabolites for in vitro biological testing. Alternatively, the active site can be assessed through a combination of in silico and in vitro approaches. Although there have been many in silico studies for anticancer compounds and Alzheimer's derivatives, relatively few studies have examined alkaloids for potential antimicrobial activity, or activity against NTDs or other tropical diseases [164-168].

One study sought inhibitors of trypanothione reductase, which is important for the proliferation of Chagas' disease, and was initiated with twelve structurally diverse alkaloids bearing a conformational semblance to the trypanothione [165]. Of the twelve alkaloids chosen for in silico binding analysis, and considering the desire for sustainable sourcing, steroidal alkaloids from commercial Solanum species were selected for further in silico structure development, semi-synthesis, and biological assessment. In another study, in vitro assessment in an inhibition assay with promastigotes of Leishmania infantum, L. braziliensis, L. amazonensis, and L. guyanensis, and with intracellular amastigotes of $L$. infantum and L. amazonensis indicated that 2,3-dihydro-1-aza-benzo[de]anthracen-7-one (12) 
was an inhibitor, which was supported by in vivo activity in mice [166]. Bioinformatics identified four enzymes which could possibly serve in the future as predictors of in vivo antileishmanial activity. A set of 2194 plant-derived metabolites, including 290 diverse alkaloids, were evaluated in silico against three dengue virus proteins, however, the results indicated that polyphenolics, not alkaloids, were the strongest binding compounds [167]. In addition, from an exploratory perspective, in vitro activity of three indole alkaloids from Rauvolfia tetraphylla L. (Apocynaceae) against the filarial bovine parasite Setaria cervi was correlated with their binding characteristics and in vitro inhibition against glutathione-Stransferase (GST) [168].

In silico assessment of 39 alkaloids indicated that the $\beta$-carboline-monoterpene indole alkaloid nigritanine (13) from Strychnos nigritana Baker (Loganiaceae) showed high activity against $S$. aureus, which was verified in vitro against three clinical isolates [169]. An in silico model of the extrusor protein MexXY, which causes aminoglycoside resistance of P. aeruginosa, was used to explore its inhibition by berberine (6) in the presence of tobramycin, and the predicted effectiveness confirmed through in vitro assessment [170]. The ergot alkaloid chanoclavine I (14) from Ipomoea muricata (L.) Jacq. (Convolvulaceae) had the ability to overcome MDR in E. coli and in silico studies confirmed the binding to proteins associated with drug resistance for efflux (Figure 3) [171]. These studies are critically important to establish those enzymes which can best serve as in silico models, thereby functioning as an information source for prioritization to explore the correlations between in silico, in vitro, and in vivo activity.<smiles>CN[C@H]1Cc2c[nH]c3cccc(c23)/C1=C\C(C)CO</smiles>

Figure 3. Alkaloids featured in in silico binding studies for antibiotic resistance.

\subsection{Alkaloids to Overcome Drug Resistance}

In addition to having antimicrobial activity, can alkaloids also serve to overcome the resistance to antibiotics, antimalarial, and anti-TB agents? The monoterpene indole alkaloid reserpine (15) is a well-established standard with that capacity [172]. Further searches to find alkaloids to overcome drug-resistance in cancer cells and against drug-resistant malaria indicate that they are rare entities. Some examples include the bisbenzylisoquinoline alkaloid cepharanthine (16) [173,174] and related alkaloids [175], aglaiamide derivatives from Aglaia species [176], iboga alkaloids from Peschiera laeta (Mart.) Miers (Apocynaceae) [177], the aporphine alkaloid roemerine (17) from Annona senegalensis Pers. (Annonaceae) [178], the tropane polyesters, the pervilleines (e.g., 18), from Pervillea sp. Decne. (Apocynaceae) $[179,180]$, lamellarin $\mathrm{O}(19)$ from the marine sponge Ianthella sp. [181], and oxymatrine (20), which overcomes inhibition to hepatitis B infection (Figure 4) [182]. These alkaloids are typically active at a lower dose than either of the two positive control compounds reserpine (15) and verapamil. Several of these groups of alkaloids merit further study for their mechanism of action in overcoming drug resistance. 
<smiles>COC(=O)[C@@H]1C(OC(=O)c2cc(OC)c(OC)c(OC)c2)[C@@H]2C[C@@H]3c4[nH]c5cc(OC)ccc5c4CCN3C[C@@H]2C[C@@H]1OC</smiles>

reserpine (15)

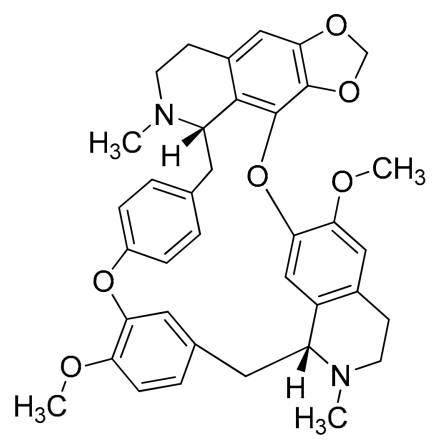

cepharanthine (16)<smiles></smiles>

roemerine (17)<smiles>COc1cc(/C=C/C(=O)OC2CC3CC(OC(=O)/C=C/c4cc(OC)c(OC)c(OC)c4)C(C2)N3C)cc(OC)c1OC</smiles>

pervilleine C (18)<smiles>COC(=O)c1c(-c2ccc(O)cc2)cn(CC(=O)c2ccc(OC)cc2)c1C(=O)OC</smiles>

lamellarin O (19)<smiles>O=C1CCCC2C3CCC[N+]4([O-])CCCC(CN12)C34</smiles>

oxymatrine (20)

Figure 4. Alkaloids with properties to overcome drug resistance.

\subsection{Transformation of Alkaloids}

The chemical modification of known alkaloids to explore structure activity relationships (SAR), or to assess for new biological responses, is an important aspect of the drug discovery process, and can be either highly targeted based on lipophilicity $(\log P)$ or in silico binding considerations. Among the alternative methods to be applied for altering the initial alkaloid structure are chemical transformations, microbial transformations, and biocatalysis.

Morphine, atropine, cocaine, aconitine, penicillin, cephalosporin, vinblastine, and camptothecin have each served in the past as alkaloid scaffolds for modification to improve potency, diversify their applications, or reduce toxicity [2]. Hundreds of derivatives have been synthesized based on the original alkaloids, and some products, particularly in the morphine alkaloid [183-185] and the cephalosporin and penicillin [186,187] series, have become important drugs.

\subsubsection{Chemical Transformations}

Creating compounds which explore biological space in a rational manner is an important aspect of the discovery process; even though, at least in the past, it may have been an untargeted and somewhat empirical approach, it was the basis for the explorations of combinatorial chemistry with large libraries of synthetic compounds [188]. Modifications of biologically active alkaloids have long been used to explore structure activity relationships 
and the potentiation of activity or, more recently, to overcome drug resistance to antibiotics. Most of these transformations are straightforward, and in contemporary chemistry some would classify them into the "click" category, particularly when the original sample size is limited [189]. "Click" chemical reactions, which evolved from the combinatorial chemistry strategy for drug discovery, are characterized by consistently high yields, easy to perform, simple clean-up, little or no purification, no need for inert atmosphere or strict exclusion of water, and the use of readily available reagents. Since the first demonstrations, reviews of the strategy from a drug discovery perspective have appeared [190-192]. Some of the reaction options include [189]: cycloaddition reactions (1,3-dipolar- and hetero-Diels-Alder); nucleophilic opening of small heterocyclic systems, such as oxiranes and aziridines; formation of ketocarbonyl derivatives; and the products from reactions on double bonds. One can envisage that several alkaloid structure types could benefit from the application of this chemistry to form new compound libraries for assessment.

A quite different approach to developing structural diversity in natural products is to conduct chemical reactions, such as reductions, oxidations, halogenations, aminations, hydrolyses, etc., directly on plant or microbial extracts seeking to modulate the observed biology $[128,193]$. Beyond the application of acids to serve as hydrolytic reagents, several reports using this approach have resulted in the creation of bioactive compounds from inactive extracts [194-197], as well as developing new scaffolds for bioactivity assessment [198-200]. Chemically profiled extracts of monoterpenoid indole alkaloid-containing plants, whose alkaloids are both highly functionalized and bioactive, would be an interesting and viable target for such an empirical study.

\subsubsection{Microbial Transformations}

Microbial transformation of purified alkaloids is an alternative, empirical strategy for structure modification, although the yields are typically not high. The original regio- and stereoselective $11 \alpha$-hydroxylation of progesterone (21) by a Rhizopus spp. at the Upjohn Co. in 1952 was critical, as it demonstrated the potential to create new centers for chemical development at an unreactive site reproducibly on a large scale [201]. In alkaloid chemistry, it is an under-explored area as a method to introduce functionalization at unreactive sites. In addition, it has not been used extensively for functional group modification or transesterification reactions to explore modifying levels of bioactivity [202,203]. The most important example for an alkaloid is the introduction of a $14 \beta$-hydroxy group into the morphinan skeleton by Pseudomonas putida M10, which increases analgesic potency, and was studied as a high yielding industrial process for the formation of hydromorphone and hydroxycodone [204,205]. The transformation of nicotine (22) by Arthrobacter nicotinovorans has also been of industrial interest [206,207]. This neglected area of alkaloid chemistry needs more explorations particularly if yields can be enhanced, and the breadth of organisms studied expanded, with an emphasis on gene manipulation to enhance substrate acceptability.

In addition to the functionalization of purified alkaloids, further exploration into microbial transformations as a route to the production of known alkaloids may offer more sustainable approaches to sourcing alkaloids. A good example of this application was demonstrated by Brown et al., where the monoterpene indole alkaloid progenitor strictosidine (23), was produced by yeast, and was then modified by the removal of three genes and the introduction of 21 new genes [208]. In 2014, a 10-gene plant pathway in yeast was reconstituted which produced dihydrosanguinarine (24) (Figure 5) [209]. Reconstituting plant biosynthetic pathways in microbial hosts as a factory for alkaloid production is proving to be an attractive alternative. In addition to a potentially more sustainable approach to the sourcing of alkaloids, hybrid biosynthetic pathways may also be constructed to facilitate de novo alkaloid modifications [209]. This demonstrates the feasibility of the use of microbial systems as a source of new and known alkaloids [209]. However, further work is required to facilitate the transition to industrial scale drug discovery, some aspects of which have been outlined by Courdevault et al. [210]. 
<smiles>CC(=O)[C@H]1CC[C@@H]2[C@@H]1CC[C@H]1[C@H]2CCC2=CC(=O)CC[C@@]21C</smiles>

progesterone (21)<smiles>CN1CCC[C@H]1c1cccnc1</smiles>

nicotine (22)<smiles>C=C[C@@H]1[C@H](O[C@@H]2O[C@H](CO)[C@@H](O)[C@H](O)[C@H]2O)OC=C(C(=O)OC)[C@H]1C[C@H]1NCCc2c1[nH]c1ccccc21</smiles>

strictosidine (23)<smiles>CN1Cc2c(ccc3c2OCO3)-c2ccc3cc4c(cc3c21)OCO4</smiles>

dihydrosanguinarine (24)<smiles>O=Cc1ccccc1</smiles>

benzaldehyde (25)

Figure 5. A small selection of alkaloids which have been subjected to microbial transformation, and progesterone (21) and benzaldehyde (25).

\subsubsection{Biocatalysis}

The use of enzymes for the development of new compounds has a long history [211], beginning with the conversion of benzaldehyde (25) with HCN in the presence of emulsin from almonds [212]. Over time, drawbacks in using biocatalysis became evident, including the lack of regio- and stereo-predictability, the low yields, and product feedback inhibition [211]. However, directed evolution involving gene mutagenesis, expression, and functionality screening has approached some of these concerns, and will undoubtedly continue to enhance this as an important approach for alkaloid diversification [213]. More functional details are necessary to foster the precise mutations that can be made for the development of selected, stable, reusable enzymes having wide substrate capacity as robust reagents for oxidations, reductions, esterifications, hydrolyses, and cyclization reactions, etc. [214], and to effect reactions at normally inaccessible sites.

The combination of enzymatic and non-enzymatic catalysts (cooperative catalysis) offers an alternative to the functionalization of inactivated or inaccessible sites, as well as promoting the interconversion of starting material to enantiomers [215]. There are a few examples of the enzyme engineering [216], one of which includes the use of a bifunctional artificial metalloenzyme comprised of streptavidine engineered with aspartic and glutamic acid residues with a docked biotinylated Rh(III) complex [217]. The metalloenzyme allowed for asymmetric C-H activation, which was used to access dihydroisoquinones [217]. These approaches, however, need more refinements to ensure industrial and sustainable applications. Perhaps a greener and more sustainable process could present itself as a one-pot chemo- and biosynthetic approach [218].

Another facet to consider is that the inclusion of biocatalytic options in AI systems, for consideration in retrosynthetic analysis, is imperative [219] in realizing greener synthetic protocols. The development of bacteria-originating enzymes for specific chemical transformations is also an approach that requires enhanced development, particularly from a commercial perspective to produce catalytic systems which can be stabilized and embedded through 3D-printing and then re-utilized. It is also well-established that whole plant parts can be used to effect high-yielding, enantioselective carbonyl reduction and acyltransferase reactions [220].

\subsubsection{Application of Nanotechnology}

There are multiple scientific reports on the isolation, bioactivity, and bioavailability of alkaloids, each facet with their own drawbacks. Over the years, the emergence and 
combination of nanotechnology to drug discovery has proven quite beneficial [221]. Reports indicate that the use of nanoparticles of perlite, perlite- $\mathrm{TiO}_{2}$, multi-walled carbon nanotubes (MWCNTs), and MWCNT-COOH, among others, result in the improved yields of secondary metabolites from plants such as Hypericum perforatum L. (Hypericaceae), Salvia verticillata L. (Lamiaceae), Catharanthus roseus (L.) G.Don (Apocynaceae), and Salvia nemorosa L. (Lamiaceae) [222]. Additionally, silver nanoparticles increased the production of tryptanthrin in Isatis constricta P.H. Davis (Brassicaceae) 1.71-fold [223]. Challenges remain, including phytotoxicity and oxidative stress associated with the use of nanoparticles as a treatment for medicinal plants. However, further research may offer a sustainable process for the common use of nanoparticles as additives to medicinal plants to increase alkaloid yields.

There has been a recent rapid development in the production of nanoparticles of alkaloids to examine their biological properties. For example, berberine (6) nanoparticles, prepared through the evaporative precipitation of a nanosuspension, showed enhanced antimicrobial activity against Gram-positive and Gram-negative bacteria and yeasts [224]. Encapsulation of ergot alkaloids has also provided enhanced bioactivity, by way of improved bioavailability, in ocular drug administration [225]. These two examples reveal the importance of combining nanotechnology with the drug discovery process of both known and new alkaloids.

\subsubsection{Repurposing and the Follow-Up of Known Alkaloids}

The repurposing of the diverse scaffolds of alkaloids which have been approved for other indications [2] offers a viable approach to addressing urgent needs, or when the potential patient pool is so small that a formal discovery process through larger-scale screening could not be justified [226]. An overview of drug repurposing efforts has been compiled [227]. Any library of compounds for biological evaluation in a new test system should have a core set of alkaloid scaffolds, including all those that are established as approved drugs, as well as 50-80 additional alkaloids from sustainable sources. One example that has already shown to offer dual use is the alkaloid colchicine (26). Wellknown as an alkaloid for the treatment of gout, it showed good effectiveness for the treatment of familial Mediterranean fever and was approved for this use in 2009 [228].

Due to the challenges of acquiring an adequate collection of alkaloids in a single location with appropriate bioassay capacity, alternative approaches to repurposing have been adopted. One strategy has been to target specific organisms, such as helminths [229], or a specific disease, such as diabetes [230]. The reverse process considers a set of drugs for a disease, for example immunomodulators [231], or the CNS [232], with retesting for other specifically desired indications. An in silico study of 92 alkaloids in 10 structure classes from Papaver species examined the structure-activity relationships through chemoinformatics and generating heatmaps for a broad range of receptors, and serves as a potential model strategy [233]. The importance of large datasets of biological options for docking is critical, as well as the need to consider the sustainability of sourcing as "hits" are accumulated. It is also important to recognize the opportunity to keep testing in silico with all the many available model targets [234].

In silico binding studies rapidly became important in discovery initiatives for the ongoing SARS-CoV-2 virus (COVID-19) pandemic, and colchicine (26) has been studied as a potential antiviral agent [235]. The assessment of different scaffolds for utility at various stages in the SARS-CoV-2 disease evolution is a rapidly expanding activity in drug discovery [236,237], particularly using in silico techniques [238-240], providing some hits for further analysis in vitro. Four of the 13 alkaloids evaluated from Cryptolepis sanguinolenta (Lindl.) Schltr. (Apocynaceae), namely cryptomisrine (27), cryptospirolepine (28), cryptoquindoline (29), and biscryptolepine (30), were identified as having strong binding energies with the main protease and the RNA-dependent RNA polymerase of SARS-CoV-2 [238]. Anisotine (31) from Justicia adhatoda L. (Acanthaceae) also bound strongly to the main protease [239], as did thalimonine (32), sophaline D (33), tomatidine 
(34), and emetine (35) in a study of 17 alkaloids (Figure 6) [241]. These approaches can also serve as a model for discovery for NTDs where critical enzymes can be identified and modeled.<smiles>COc1ccc2c(c1)C(NC(C)=O)CCc1cc(OC)c(OC)c(OC)c1-2</smiles>

colchicine (26)<smiles></smiles>

cryptoquindoline (29)<smiles>COc1cc2c(c3c1OCO3)CC1c3ccccc3CC2N1C</smiles>

thalimonine (32)<smiles>O=C(c1c2ccccc2nc2c1[nH]c1ccccc12)c1c2ccccc2nc2c1[nH]c1ccccc12</smiles>

cryptomisrine (27)<smiles></smiles>

biscryptolepine (30)<smiles>CN1C(=O)n2c3c(c4ccccc42)C(=Cc2c([nH]c4ccccc24)N3C)c2ccccc21</smiles>

cryptospirolepine (28)<smiles>COC(=O)c1cc(C2CCn3c2nc2ccccc2c3=O)ccc1N</smiles>

anisotine (31)<smiles>CC(=O)c1cc(C)c2c(c1)N1CCC[C@@H]3CN4C(=O)CCC[C@H]4[C@H]3[C@H]21</smiles>

sophaline D

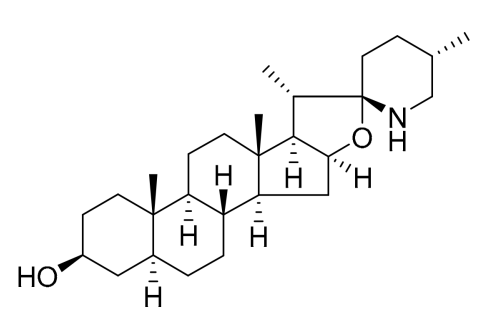

tomatidine (34)<smiles>[R]Oc1cc2c(cc1OC)[C@H](C[C@@H]1C[C@@H]3c4cc(OC)c(OC)cc4CCN3C[C@H]1CC)NCC2</smiles>

Figure 6. Examples of alkaloids to consider for repurposing as a drug discovery strategy.

Another aspect of repurposing which covers resource minimization is follow-up, i.e., examining the literature, assessing the existing data, and considering whether further studies are warranted. Some examples relating to leishmaniasis and malaria will illustrate. Simple 2-alkylated quinoline alkaloids, such as chimanine B (36) from the stem bark and leaves of Galipea longiflora K. Krause (Rutaceae) and synthetic 2-propylquinoline (37), were effective against CL and VL in a mouse model [241,242]. This would appear to be a very promising scaffold for exploratory SAR studies, as analogues are readily synthesized. 
The Psychotria (Cephaëlis) alkaloids also show activity against $L$. donovani isolates [243]. Cephaeline (38) was active $\left(\mathrm{IC}_{50} 0.06 \mu \mathrm{M}\right)$, but cytotoxic, whereas klugine (39), the 6-Omethyl ether derivative, was less active $\left(\mathrm{IC}_{50} 0.85 \mu \mathrm{M}\right)$ and not cytotoxic [243]. Finally, a marine metabolite, renieramycin A (40) from a Neopetrosia species, showed an $\mathrm{IC}_{50}$ of $0.35 \mu \mathrm{M}$ against L. amazonensis (Figure 7) [244].<smiles>C/C=C/c1ccc2ccccc2n1</smiles>

chimonine B (36)<smiles>CCCc1ccc2ccccc2n1</smiles>

2-n-propylquinoline (37)<smiles>CC[C@H]1CN2CCc3cc(O)c(OC)cc3[C@H]2C[C@@H]1C[C@]1(O)NCCc2cc(O)c(OC)cc21</smiles>

klugine (39)<smiles>C/C=C(/C)C(=O)OC[C@H]1C2=C(C[C@H]3C4C(=O)C(OC)=C(C)C(=O)C5=C4CN3[C@H](C2)[C@@H]5O)C(=O)C(C)=C1OC</smiles>

renieramycin $\mathrm{A}(\mathbf{4 0})$

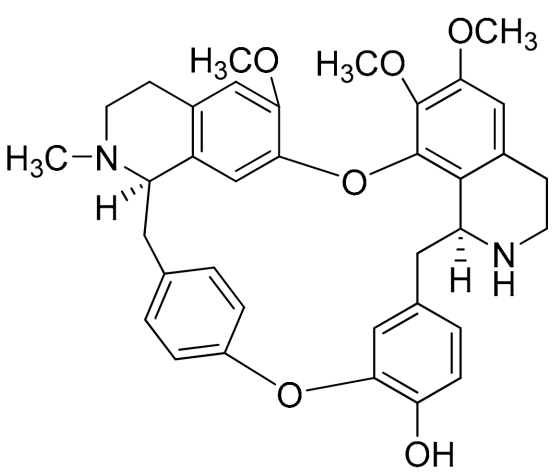

2-norberbamine (41)

Figure 7. More examples of alkaloids warranting further consideration.

The examination of 16 medicinal plants used in Thailand for malaria and available in the marketplace, in the standard Plasmodium falciparum assays, revealed 12 to be active, from which four groups of alkaloids (aporphines, bisbenzylisoquinolines, 5,10bethanophenanthridines, and tetrahydroprotoberberines) were shown for the first time to possess selective antimalarial activity [245]. The activity of 2-norberbamine (41) (SI 2400) was particularly noteworthy. Those discovery opportunities based on available medicinal plants remain to pursued. Strategies for the repurposing of alkaloids through a combination of in silico binding studies and in vitro testing, coupled with up-front considerations of sustainability and accessibility, will evolve as both a functional strategy for identifying new opportunities, and a predictive approach based on artificial intelligence applications. A quite different aspect of repurposing centers on the evolution of genomic approaches to understand all the nodes where an alkaloid is operating as a part of network pharmacology (vide infra) [246-248].

\subsection{Genomics-Based Discovery}

Discovering new alkaloid scaffolds from microbial sources has evolved dramatically with the availability of more complete genomes, and the bioinformatics applications supporting analysis of the data. Two disclosures have been critical in opening the opportunities for new alkaloids to be generated and tested: the structures of the biosynthetic gene clusters 
(BGCs), and the presence of cryptic clusters. Unlike the pathways for metabolite formation in plants, the genes encoding for the biosynthetic enzymes in microorganisms are clustered and highly organized. For polyketide synthases (PKS) and non-ribosomal peptide synthases (NRPS), they have characteristic domains for performing specific biosynthetic pathway steps. Gene clusters for certain NRPS, PKS, and NRPS/PKS hybrid alkaloids can be identified through a genome mining bioinformatics approach, as a form of dereplication and discovery [249].

As more gene clusters have been analyzed in silico, organisms are revealed to have the genetic capacity to produce many more metabolites in different classes than previously observed [250]. Actinobacteria were identified as a good resource [251], as well as Gram-negative bacteria in the genera, Pseudomonas, Clostridium, and Burkholderia [252,253], cyanobacteria [254], and marine sponge-associated bacteria [255]. Fungi (e.g., Aspergillus sp.) are considered an even better source of cryptic biosynthetic clusters [256].

These "silent" pathways can constitute the majority of the identified BGCs, and frequently represent unidentified compounds. For example, Streptomyces coelicolor A3(2) had six identified metabolic pathways with 16 BGCs encoding for unknown metabolites [250]. Based on the domains for substrate activation of the BGCs [257], those likely to produce alkaloids, i.e., the NRPS and NRPS/PKS clusters, are easily identified [258], and represent a significant opportunity $[249,259,260]$. The identification of BGCs having unrecognizable modular characteristics probably indicates new scaffolds [261-263] and the characterization of new alkaloid structures [264-268]. The profound challenge is to activate the pathways selectively, or in a heterologous host [260,269-273]. An excellent summary of these techniques and the range of chemical outcomes is available in [260].

At the present, a complete natural product structure cannot be predicted de novo from a new biosynthetic gene cluster; although algorithms may assist [274], heterologous expression of the BGC and conducting the isolation and structure elucidation is required. Once non-functional modules can be unambiguously identified in silico, and substrate specificities defined, levels of structure prediction for an assembled pathway product will be enhanced.

Searching NRPS motifs will yield alkaloids. An assessment of 830 genome sequences of Actinobacteria comprised 11,422 gene clusters which were grouped into 4122 families [249]. Three taxons are considered the most important for their BGCs, the Streptomycetales, the Pseudonocardiales, and the Streptosporangiales, which account for $80 \%$ of the NRPS BGCs. Mass spectral analysis of the products from 178 strains grown in four different media revealed an average of 105 compounds/strain, represented by 2251 individual metabolites. Twenty-seven known metabolites were correlated with their BGC and verified in the samples 268 times. Hence, dereplication is necessary to avoid unwanted metabolite redundancy purification. Based on the known Actinobacteria, hundreds of thousands of metabolite scaffolds probably remain to be characterized, with closely related analogs also being produced [249].

\subsection{Applications of Metagenomics}

Opportunities exist for assessing ecological environments holding clues to new drug discovery through the resident extremophiles [275] and represent a classic opportunity for metagenomics [276-278]. Metagenomics is a method, independent of cultivation, for the collective examination of the microbial genomes in a particular habitat [279], particularly for new metabolites [276,280,281]. It was greatly enhanced by high-throughput DNA sequencing technologies and database access to established BGC sequences. This has allowed microbial communities to be analyzed at the ecosystem level [278]. Functionbased screening was a successful approach for the cyanobactin polypeptide macrolide alkaloids [282]. Achievements in identifying new, skeletally diverse alkaloids and other metabolites through the metagenomics approach, as well as the barriers to success related to the expression of genes in heterologous hosts, have been discussed [283,284]. For the 
future, the interlacing of machine learning with bioinformatics and synthetic biology will be crucial in the further development of metagenomics and for new alkaloid discovery.

\section{Alkaloids and the Fourth Industrial Revolution}

\subsection{Industry 4.0 (4IR) and the Quintuple Helix}

Cognizant of the limitations of "conventional technologies", the issues associated with alkaloid drug discovery for global disease needs warrants the extensive application of integrated technologies which can offer new perspectives and approaches for more systematic and sustainable research outcomes. Seven of the twelve recognized technologies associated with the Fourth Industrial Revolution (4IR) [17] impact natural products and drug discovery, they are: artificial intelligence (AI) and AI systems, ubiquitous linked sensors, new computing technologies, 3D printing, advanced materials and nanomaterials, biotechnologies, and neurotechnologies [20]. These technologies operate in concert with the Quintuple Helix, which extends the models for driving creativity, innovation, and development in science and engineering [19]. The Triple Helix focuses on the interrelationships between academia, industry, and government for enhancing innovation in various sectors. The Quadruple Helix adds the context of a "knowledge society", in which successive exchanges of knowledge between the scientific, engineering, and technology sectors stimulate innovation in another sector. The exchanges promote "knowledge democracy", which, coupled with the globalization of the internet and other communications systems, allows for instantaneous and equal access to datasets of accrued knowledge irrespective of their location(s) [285]. The Quintuple Helix coalesces the ecologically sensitive component and a healthy populace with the knowledge society derived from the collaboration of academia, industry, and the government into creativity and innovation. It is fundamental to sustainable drug discovery, and due to the extensive prior data from a long history of effective use, can specifically involve alkaloids in the creative process $[18,286]$. This integrated approach stands as an essential aspect of the "green knowledge" solutions to human issues [287], optimizing the use of natural resources while conserving them, a component of the United Nations Sustainable Development Goals [54]. Consideration of the environmental impact and sustainability early in the drug discovery process are aspects of ecopharmacognosy $[129,130]$. That will inspire creativity and innovation for the potentiation of natural resources, including alkaloids, to meet global health needs, through the integration of the existing and evolving technologies in terms of cyberecoethnopharmacolomics (CEEPO) [20,288]. This level of integration, while currently not a realistic expectation for most of the world, should be considered a goal for the future.

\subsection{Artificial Intelligence in Drug Discovery}

The past fifteen years have witnessed the dramatic impact of artificial intelligence (AI) in drug discovery in the pharmaceutical industry [289-295], including the development of automated and complete compound design cycles as ultra-HTS systems [296]. Outside of Big Pharma, fully integrated design systems will focus on smaller, highly targeted libraries [297] which are more conducive for the assessment of characterized and semipurified plant, marine, and fungal extracts.

To enhance the assessment of known and new alkaloids, the speed of screening is not the key issue as the sample numbers are limited. Success will arise through generating active-site binding affinity data [298], establishing alkaloid sustainability, and the targeted assays. Advanced AI systems applications to libraries of alkaloids, selectively modified and tested on an iterative basis, in conjunction with chemically primed, 3D-printed modules introducing successive reaction steps, will become a routine practice [299,300].

Automated recognition of feasible synthetic processes (oxidation, reduction, hydrolysis, esterification, aromatic substitution, etc.) for a particular sustainable alkaloid structure will lead to autonomous design profiles conducted by an AI system [301]. Until a system is "trained" through machine learning, only a balance between human creativity, automation, and artificial intelligence/machine learning, will identify "leads". Considerations of drug- 
off-target interactions and bioavailability assessments in early phase synthetic options will be critical for efficiency. Five "grand challenges" in the rethinking of drug design [294] were cited as: obtaining appropriate datasets, generating new hypotheses, optimizing in a multi-objective manner, reducing cycle times, and changing the research culture.

Within this discovery framework lies network pharmacology, the holistic approach of considering a single compound to have multiple nodes of action [246-248]. Systematic mapping through AI of the action sites at an early stage may yield indications about interactions with other drugs from a synergistic or antagonistic perspective, providing glimpses of potential toxicity issues [302], and should reduce the high levels of attrition occurring in the clinical trials stages [303]. The Universal Natural Products Database [234] comprising (in 2013) 197,201 natural products is a resource to explore natural product structure diversity, space, drug-likeness, and biological perspectives. It was docked against 332 target proteins of FDA-approved drugs, which revealed that natural products occupied a more expansive space than synthetic drugs, implying a far greater diversity of potential biological properties for future discovery, particularly as more diverse biological systems are explored [234]. Although the average number of targets for natural products was 2.66, two IMPS/PAINS compounds, the indolocarbazole alkaloid staurosporine (42) with 298 targets, and the widely distributed flavonoid quercetin (43) with 82 targets, were of particular interest [141-143]. The paucity of published biological reports for the vast majority $(98.2 \%)$ of the natural products in the database was noted. For enhanced benefit to be derived, an important question to be asked is "What are the active site space requirements that need to be filled?", especially as the space-filling profiles of the FDA-approved drugs are so limited. This particularly applies to the characterized NTD active sites and drives the need for further active site characterization for disease inhibition to match alkaloid scaffolds and their tailoring.

The Connectivity Map (CMap) at the Broad Institute in Cambridge, MA is an important resource for examining the impact of small molecules on gene expression. It has over 1.5 million gene expression profiles derived from $\sim 5000$ compounds and $\sim 3000$ genetic reagents, evaluated in multiple cell types, and can be used to search for compounds having a gene expression profile corresponding to a specific disease phenotype [304]. Other systems for predicting therapeutic outcomes for natural product small molecules have also been presented [248]. One outcome was identification of the quinolizidine alkaloid matrine (44) to act synergistically with the anti-angiogenic activity of the enantio-morphine alkaloid sinomenine (45). Interestingly, these two metabolites are important alkaloid constituents of the TCM formula Qing-Luo-Yin which is used to treat angiogenesis [305,306].

\subsection{Machine Learning}

Machine learning (ML) is the application of algorithms which perform explorations through pattern recognition in large data sets $[307,308]$. It is evolving as an essential tool in contemporary alkaloid drug discovery. The algorithms of ML may be either supervised (indicating sorting to predefined categories), or unsupervised in which clusters are created and classification occurs through application of the algorithms. The ability to adjust and "learn" during the sorting process, or processes, allows for more meaningful implications to be drawn from large datasets. Learning establishes layers of deep neural networks (DNNs) which interrelate sets of data and have become a fundamental tool in contemporary drug discovery [309-311] through applications to high throughput screening (HTS) and quantitative structure activity relationship (QSAR) analyses [312,313], pattern recognition [314], identifying possible drug-target interactions [315], and for detecting and monitoring drugresistant pathogens [316]. Enhanced facility in applying algorithms to specific datasets will be an important step to improve accessibility for the non-chemoinformatics specialist. One recent successful DNN application was the identification of an interesting new scaffold for an antimicrobial in halicin (46) [316]. Halicin (46) was active against Mycobacterium tuberculosis and carbapenem-resistant enterobacteria in vitro, and against Clostridioides difficile and pan-resistant Acinetobacter baumannii in vivo. ML models for compounds active 
against Chagas' disease using the Broad Institute set of analogs revealed five compounds which tested positive against $T$. cruzi in vivo, including the synthetic antimalarial drug pyronaridine (47) (Figure 8) [317].

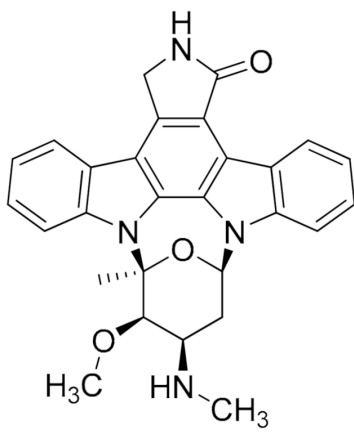

staurosporine (42)<smiles></smiles>

quercetin (43)<smiles>O=C1CCC[C@H]2[C@@H]3CCCN4CCC[C@@H](CN12)[C@@H]34</smiles>

matrine (44)<smiles>COC1=CC[C@@]23Cc4ccc(OC)c(O)c4[C@@]2(CC=C(OC)N(C)C3)CC1=O</smiles>

sinomenine (45)<smiles>COc1ccc2nc3cc(Cl)ccc3c(Nc3cc(CN4CCCC4)c(O)c(CN4CCCC4)c3)c2n1</smiles>

pyronaridine (47)<smiles>Nc1nnc(Sc2ncc([N+](=O)[O-])s2)s1</smiles>

halicin (46)<smiles>COc1ccc2c3c1OC1CC(=C[C@@H](O)C1)[C@@H]23</smiles>

galantamine (48)

Figure 8. Representative bioactive alkaloids and quercetin (43).

Recent applications of machine learning have included searching for the structural parameters important for antimalarial activity [318], classifying natural and synthetic molecules in large data sets of $300 \mathrm{~K}$ structures and quantifying natural product likeness [319], and searching for mimetics of the expensive Alzheimer's drug, the Amaryllidaceae alkaloid galantamine (48), from 3,383,942 compounds [320]. Machine learning has been used to prioritize the application of biological screens using published bioactivity data [321] and, based on spatial considerations, to classify a database of 25,523 natural products from bacterial and fungal sources [322]. An interesting outcome from the latter study was the ability to predict fungal or bacterial origin through analysis of the structure.

"End-to-end" (E2E) machine learning in drug discovery [323] has been proposed as a standard practice across all aspects of the discovery process [324,325]. In this way the design, synthesis, identification, and the presentation and biological testing of compounds, irrespective of origin, will be enhanced [326]. Through the application of multiple 
algorithms, smaller corporate and academic research programs should be able to identify more compounds for assessment against rare or neglected diseases [317]. In spite of some limitations [323], the ChEMBL database may be especially useful with respect to targeting compounds and biological testing [327]. With its available expertise and dataset assets, Big Pharma could do much more to both encourage and sponsor new drug discovery efforts for NTDs and new antibiotics between small companies and academia, activities which will always be outside their discovery realm. Their role will likely occur when their clinical development capabilities would be beneficial.

A recent review summarized the global distribution of some of the databases currently operational in the natural products community, many of which are only locally accessible [328]. For effective practices in the context of the Quintuple Helix, interoperability and accessibility to create knowledge parity are key elements. One vision is to develop a natural product data portal for the input and egress of information, which would link key databases relating to taxonomy, ethnomedicine, chemistry, biology, and spectroscopy, etc. to achieve a globally accessible resource for the evolution of natural products research [329]. If achieved, this would constitute the disruptive innovation for the analysis of natural products research priorities. The sourcing and sustainability requirements are critical elements in analyzing large compound datasets as metabolites are identified for biological assessment.

The unification of machine learning and genomics discussed previously represents a powerful combination of technologies for the future diversification of natural product structures, especially alkaloids, in drug discovery, and in a targeted manner [330]. Natural products are regarded as already in nature, and thus a discovery source. New choices abound for the design and creation of new molecules from nature, an aspect of combinatorial biosynthesis. Advances in BGCs genomic information, the interweaving of large biological datasets, and the introduction of AI systems for programmed genetic manipulation processes, and for examining culturing options, in conjunction with in silico efforts to identify specific structure modifications of biological relevance, will bring focus to a fully integrated design approach for new "natural" alkaloids for testing.

Will a laboratory AI system be able to achieve those biosynthetic and biological processes in the natural product arena, as they do now for compounds derived through organic synthesis? Feedback loops for structure function relationships for in silico analysis will foster the determination of new pharmacophores which can be enhanced through machine learning. Will machine learning lead to suggestions for new functionalized alkaloid scaffolds for biosynthesis? Can that creative process be driven towards an optimized series of innovative compounds for further examination against NTDs? Such prospects are exciting indeed.

\section{A Way Forward}

In the present drug development model, the financing of drug discovery to produce a successful clinical entity in the marketplace rests with a few large pharmaceutical companies. Only $10 \%$ of potential medicinal agents survive clinical assessment, raising the estimated development costs to as high as USD 2.8 billion, depending on the therapeutic indication [331]. That level of investment is not, and cannot be, made for a single drug for the NTDs and other world diseases in need. Global pharmaceutical companies are not, and will not be, developing drugs to meet the need for drugs for the rare diseases, NTDs, malaria, or tuberculosis [55,332]. Repeating the same processes and waiting for a drug to "appear" is not a solution for a country to address the contemporary need for a new drug for the local scourge. Collaborative initiatives based on the Quintuple Helix and integration with the technologies of 4IR across borders are going to be the only way forward.

That will take putting the global patient first and will indicate that reprioritization of investment is required to create a new paradigm of drug development. Given the continuing success of natural products in drug discovery over the past 40 years [56], and the abundant natural resources in the areas of the world in greatest need of new drugs, that should be a clear natural product development priority at the international level. In 
this Fourth Industrial Revolution, the prime factors for a paradigm shift in natural product drug discovery are present: the unexplored biological and chemical resources of nature, the vast amounts of stored data on the chemistry and biology of natural products yet to be analyzed, the technologies for the creation of in-field biosensors, AI systems for the automated isolation of bioactive metabolites, and for the optimization of natural product structures through in silico assessment of receptor interactions at the genome level.

The transference of technologies from the developed pharmaceutical industries must become a major investment for middle-income economies where scientific (including personnel) and technological infrastructure is poised for the successful development of medicinal agents to meet local prevalent disease needs. Such initiatives will build intellectual, physical, and economic resources as new industries evolve and centers of excellence are created. Two factors are missing: intent and financing. It requires consortium commitment from governments, industry, and academia in a neutral environment, such as sponsorship through a global foundation or agency, to assemble the parties to discuss, decide on priorities, and act innovatively. Model studies with well-designed disease-based priorities, programs, and performance targets will be needed. The answer to the question of "What is the most important aspect of natural product research?" is not related to technology, or scientific infrastructure, or even information systems. It is "collaboration". It is how natural product scientists and technologists in the many different areas embraced by the seven aspects within 4IR identified earlier can innovate at the interface of chemistry, biology, and technology to create new medicinal agents which can be safe, effective, and accessible to challenge the unmet health needs of the society. The vibrant history of alkaloids in the past 115 years indicates that, as a class of natural product, they should have a very important role to play in future global health care.

\section{The Need for a Third Class of Medicinal Agents}

If the extraordinary costs (up to USD 2.8 billion) to develop a new drug in the present regulatory system are a barrier to drug discovery and development for diseases outside the Big Pharma paradigm, then a new framework is needed [21]. As Buckminster Fuller said "...to change something, build a new model that makes the existing model obsolete". The creations of the internet and the smartphone are recent examples. That is the opportunity for alkaloids and the Fourth Industrial Revolution, interwoven with the development in scientific society of the Quintuple Helix. The paradigm shift required is to establish a third class of natural product drugs which cost much less to develop, are based on sustainable (local) natural sources, are a standardized preparation, are established experimentally as safe and effective, and will have gone through more limited, structured clinical trials. It is a necessary cost-effective, risk-averse step which should be promoted at the international level to address the numerous global disease issues, including multidrug resistance, malaria, tuberculosis, and the rare and neglected tropical diseases (NTDs).

\section{Conclusions}

There is much still to be learned about alkaloids and their beneficial role in health care. The marine and terrestrial biomes have enormous unexplored potential for disclosing the presence of new scaffolds. The era of 4IR and the Quintuple Helix bring together the power of large data systems, artificial intelligence, machine learning, laboratory AI systems, and knowledge exchange based on collaborative integrated and environmentally sensitive programs which can evolve for the generation of new, biologically significant molecular entities through the sustainable assessment of known alkaloids.

A new international paradigm for natural product discovery and development is necessary to meet the medicinal agent requirements for the treatment of multidrug resistant diseases, rare and neglected tropical diseases, and for malaria and tuberculosis. The natural, physical, and technological resources are present or under rapid development. Fiscal commitment and international consortia with intent are needed to transform the existing paradigm and envision an approach which optimizes the rapid developments 
of 4IR with the innovations created within the Quintuple Helix for these diseases. A third class of drugs will foster these developments and inspire both investment and innovation. Through the application of contemporary technologies applied through human creativity, new, repurposed, and redesigned alkaloids will make an important contribution to these and other drug discovery efforts. A new and exciting era for alkaloid research is already underway.

Author Contributions: Conceptualization, G.A.C. and S.-k.D.; writing-original draft preparation, G.A.C. and S.-k.D.; writing - review and editing, G.A.C. and S.-k.D.; visualization, G.A.C. and S.-k.D.; project administration, G.A.C.; and funding acquisition, G.A.C. All authors have read and agreed to the published version of the manuscript.

Funding: The preparation of this manuscript was supported by Natural Products, Inc., Evanston, IL, USA.

Conflicts of Interest: The authors declare they have no conflicts of interest.

\section{References}

1. Debnath, B.; Singh, W.S.; Das, M.; Goswami, S.; Singh, M.K.; Maiti, D.; Manna, K. Role of plant alkaloids on human health: A review of biological activities. Mater. Today Chem. 2018, 9, 56-72. [CrossRef]

2. Funayama, S.; Cordell, G.A. Alkaloids—A Treasury of Poisons and Medicines; Academic Press: New York, NY, USA, $2015 ;$ p. 284.

3. Butler, M.S. The role of natural product chemistry in drug discovery. J. Nat. Prod. 2004, 67, 2141-2153. [CrossRef] [PubMed]

4. Carter, G.T. Natural products and Pharma 2011: Strategic changes spur new opportunities. Nat. Prod. Rep. 2011, 28, 1783-1789. [CrossRef] [PubMed]

5. Qiu, S.; Sun, H.; Zhang, A.-H.; Xu, H.-Y.; Yan, G.-L.; Han, Y.; Wang, X.-J. Natural alkaloids: Basic aspects, biological roles, and future perspectives. Chin. J. Nat. Med. 2014, 12, 401-406. [CrossRef]

6. Harvey, A.L.; Edrada-Ebel, R.; Quinn, R.J. The re-emergence of natural products for drug discovery in the genomics era. Nat. Rev. Drug Discov. 2015, 14, 111-129. [CrossRef]

7. Shen, B. A new golden age of natural products drug discovery. Cell 2015, 163, 1297-1300. [CrossRef]

8. Blunt, J.W.; Carroll, A.R.; Copp, B.R.; Davis, R.A.; Keyzers, R.A.; Prinsep, M.R. Marine natural products. Nat. Prod. Rep. 2018, 35, 8-53. [CrossRef]

9. Thomford, N.E.; Senthebane, D.A.; Rowe, A.; Munro, D.; Seele, P.; Maroyi, A.; Dzobo, K. Natural products for drug discovery in the 21st century: Innovations for novel drug discovery. Int. J. Mol. Sci. 2018, 19, 1578. [CrossRef]

10. Bernardini, S.; Tiezzi, A.; Masci, V.L.; Ovidi, E. Natural products for human health: An historical overview of the drug discovery approaches. Nat. Prod. Res. 2018, 32, 1926-1950. [CrossRef]

11. Li, F.; Wang, Y.; Li, D.; Chen, Y.; Dou, Q.P. Are we seeing a resurgence in the use of natural products for new drug discovery? Expert Opin. Drug Discov. 2019, 14, 417-420. [CrossRef]

12. Fenical, W.; Jensen, P.R. Developing a new resource for drug discovery: Marine actinomycete bacteria. Nat. Chem. Biol. 2006, 2, 666-673. [CrossRef]

13. $\mathrm{Xu}, \mathrm{X}$. New concepts and approaches for drug discovery based on traditional Chinese medicine. Drug Discov. Today Technol. 2006, 3, 247-253. [CrossRef]

14. Singh, R.K.; Tiwari, S.P.; Rai, A.K.; Mohapatra, T.M. Cyanobacteria: An emerging source for drug discovery. J. Antibiot. 2011, 64, 401-412. [CrossRef]

15. Wu, W.-Y.; Hou, J.-J.; Long, H.-L.; Yang, W.-Z.; Liang, J.; Guo, D.-a. TCM-based new drug discovery and development in China. Chin. J. Nat. Med. 2014, 12, 241-250. [CrossRef]

16. Schwab, K. The Fourth Industrial Revolution; World Economic Forum: Geneva, Switzerland, 2016; p. 192.

17. Kim, S.Y.; The Fourth Industrial Revolution and the Triple Helix. Daegu: Triple Helix Association Triple Helix International Conference. 2017. Available online: https:/ /www.triplehelixassociation.org/wp-content/uploads/2017/07/Theme-paper-THC2 017.pdf (accessed on 18 March 2021).

18. Carayannis, G.; Campbell, D.F.J. Triple helix, Quadruple Helix and Quintuple Helix and how do knowledge, innovation and the environment relate to each other? A proposed framework for a trans-disciplinary analysis of sustainable development and social ecology. Int. J. Soc. Ecol. Sustain. Dev. 2010, 1, 41-69. [CrossRef]

19. Barth, T.D. The idea of a green new deal in a Quintuple Helix model of knowledge, know-how and innovation. Int. J. Soc. Ecol. Sustain. Dev. 2013, 1, 1-15. [CrossRef]

20. Daley, S.-K.; Cordell, G.A. Natural Products, the Fourth Industrial Revolution, and the Quintuple Helix. Nat. Prod. Commun. 2021, 16, 31. [CrossRef]

21. Cordell, G.A.; Colvard, M.D. Natural products and traditional medicine: Turning on a paradigm. J. Nat. Prod. 2012, 75, 514-525. [CrossRef] 
22. Murray, C.J.L.; Lopez, A.D. (Eds.) The Global Burden of Disease. A Comprehensive Assessment of Mortality and Disability from Diseases, Injuries and Risk Factors in 1990 and Projected to 2020; GBD Series; Harvard School of Public Health, World Health Organization, World Bank: Cambridge, MA, USA, 1996; Volume I.

23. Editorial. Global health: Time for radical change? Lancet 2020, 396, 1129. [CrossRef]

24. Vos, T.; Lim, S.S.; Abbafati, C.; Abbas, K.M.; Abbasi, M.; Abbasifard, M.; Abbasi-Kangevari, M.; Abbastabar, H.; Abd-Allah, F.; Abdelalim, A.; et al. Global burden of 369 diseases and injuries in 204 countries and territories, 1990-2019: A systematic analysis for the Global Burden of Disease Study. Lancet 2020, 396, 1204-1222. [CrossRef]

25. Karimkhani, C.; Wanga, V.; Coffeng, L.E.; Naghavi, P.; Dellavalle, R.P.; Naghavi, M. Global burden of cutaneous leishmaniasis: A cross-sectional analysis from the Global Burden of Disease Study. Lancet Infect. Dis. 2016, 16, 584-591. [CrossRef]

26. Stanaway, J.D.; Shepard, D.S.; Undurraga, E.A.; Halasa, Y.A.; Coffeng, L.E.; Brady, O.; Hay, S.; Bedi, N.; Bensenor, I.M.; Castañeda-Orjuela, C.; et al. The global burden of dengue: An analysis from the Global Burden of Disease Study. Lancet Infect. Dis. 2016, 16, 712-723. [CrossRef]

27. Herricks, J.R.; Hotez, P.J.; Wanga, V.; Coffeng, L.E.; Haagsma, J.A.; Basáñez, M.-G.; Buckle, G.; Budke, C.M.; Carabin, H.; Fèvre, E.M.; et al. The global burden of disease study 2013: What does it mean for the NTDs? PLoS Neglected Trop. Dis. 2017, 11, e0005424. [CrossRef]

28. Kyu, H.H.; Maddison, E.R.; Henry, N.J.; Mumford, J.E.; Barber, R.; Shields, C.; Brown, J.C.; Nguyen, G.; Carter, A.; Wolock, T.M.; et al. The global burden of tuberculosis: Results from the Global Burden of Disease Study. Lancet Infect. Dis. 2018, 18, 261-284. [CrossRef]

29. Pisarski, K. The global burden of disease of zoonotic parasitic diseases: Top 5 contenders for priority consideration. Trop. Med. Infect. Dis. 2019, 4, 44. [CrossRef]

30. Devereaux, A.L.; Mercer, S.L.; Cunningham, C.W. DARK classics in chemical neuroscience: Morphine. ACS Chem. Neurosci. 2018, 9, 2395-2407. [CrossRef]

31. Kaufman, T.S.; Rúveda, E.A. The quest for quinine: Those who won the battles and those who won the war. Angew. Chem. Int. Ed. 2005, 44, 854-885. [CrossRef]

32. Cushnie, T.T.; Cushnie, B.; Lamb, A.J. Alkaloids: An overview of their antibacterial, antibiotic-enhancing and antivirulence activities. Int. J. Antimicrob. Agents 2014, 44, 377-386. [CrossRef] [PubMed]

33. Cordell, G.A.; Quinn-Beattie, M.L.; Farnsworth, N.R. The potential of alkaloids in drug discovery. Phytother. Res. 2001, 15, 183-205. [CrossRef] [PubMed]

34. Xu, W.; Gavia, D.J.; Tang, Y. Biosynthesis of fungal indole alkaloids. Nat. Prod. Rep. 2014, 31, 1474-1487. [CrossRef] [PubMed]

35. Pan, Q.; Mustafa, N.R.; Tang, K.; Choi, Y.H.; Verpoorte, R. Monoterpenoid indole alkaloids biosynthesis and its regulation in Catharanthus roseus: A literature review from genes to metabolites. Phytochem. Rev. 2016, 15, 221-250. [CrossRef]

36. Thamm, A.M.K.; Qu, Y.; De Luca, V. Discovery and metabolic engineering of iridoid/secoiridoid and monoterpenoid indole alkaloid biosynthesis. Phytochem. Rev. 2016, 15, 339-361. [CrossRef]

37. Singh, A.; Menéndez-Perdomo, I.M.; Facchini, P.J. Benzylisoquinoline alkaloid biosynthesis in opium poppy: An update. Phytochem. Rev. 2019, 18, 1457-1482. [CrossRef]

38. Roddan, R.; Ward, J.M.; Keep, N.H.; Hailes, H.C. Pictet-Spenglerases in alkaloid biosynthesis: Future applications in bio-catalysis. Curr. Opin. Chem. Biol. 2020, 55, 69-76. [CrossRef]

39. Desgagné-Penix, I. Biosynthesis of alkaloids in Amaryllidaceae plants: A review. Phytochem. Rev. 2021, 20, 409-431. [CrossRef]

40. Lichman, B.R. The scaffold-forming steps of plant alkaloid biosynthesis. Nat. Prod. Rep. 2021, 38, 103-129. [CrossRef]

41. Lipinski, C.A.; Lombardo, F.; Dominy, B.W.; Feeney, P.J. Experimental and computational approaches to estimate solubility and permeability in drug discovery and development settings. Adv. Drug Deliv. Rev. 1997, 23, 3-25. [CrossRef]

42. Lipinski, C. Rule of five in 2015 and beyond: Target and ligand structural limitations, ligand chemistry structure and drug discovery project decisions. Adv. Drug Deliv. Rev. 2016, 101, 34-41. [CrossRef]

43. Martens, E.; Demain, A.L. The antibiotic resistance crisis, with a focus on the United States. J. Antibiot. 2017, 70, 520-526. [CrossRef]

44. Schloss, P.; Handelsman, J. Status of the microbial census. Microbiol. Mol. Biol. Rev. 2004, 68, 686-691. [CrossRef]

45. Amann, R.I.; Ludwig, W.; Schleifer, K.H. Phylogenetic identification and in situ detection of individual microbial cells without cultivation. Microbiol. Rev. 1995, 59, 143-169. [CrossRef]

46. Hawksworth, J. Mushrooms: The extent of the unexplored potential. Int. J. Med. Mushrooms 2001, 3, 333-337. [CrossRef]

47. Hugenholtz, P.; Hooper, S.D.; Kyrpides, N.C. Focus: Synergistetes. Environ. Microbiol. 2009, 11, 1327-1329. [CrossRef]

48. Vasas, G.; Borbely, G.; Nánási, P.; Nanasi, P. Alkaloids from cyanobacteria with diverse powerful bioactivities. Mini Rev. Med. Chem. 2010, 10, 946-955. [CrossRef]

49. Shah, S.A.A.; Akhter, N.; Auckloo, B.N.; Khan, I.; Lu, Y.; Wang, K.; Wu, B.; Guo, Y.W. Structural diversity, biological properties and applications of natural products from cyanobacteria. A review. Mar. Drugs 2017, 15, 354. [CrossRef]

50. Hardoim, P.R.; Van Overbeek, L.S.; Berg, G.; Pirttilä, A.-M.; Compant, S.; Campisano, A.; Döring, M.; Sessitsch, A. The hidden world within plants: Ecological and evolutionary considerations for defining functioning of microbial endophytes. Microbiol. Mol. Biol. Rev. 2015, 79, 293-320. [CrossRef]

51. Gouda, S.; Das, G.; Sen, S.K.; Shin, H.S.; Patra, J.K. Endophytes: A treasure house of bioactive compounds of medicinal im-portance. Front. Microbiol. 2016, 7, 1538. [CrossRef] 
52. Daley, S.-K.; Cordell, G.A. Biologically significant and recently isolated alkaloids from endophytic fungi. J. Nat. Prod. 2021, 84, 871-897. [CrossRef]

53. World Health Organization. Investing to Overcome the Global Impact of Neglected Tropical Diseases; Third WHO Report on Neglected Tropical Diseases; World Health Organization: Geneva, Switzerland, 2015; p. 211.

54. United Nations Sustainable Development Goals. Available online: https://www.un.org/sustainabledevelopment/sustainabledevelopment-goals / (accessed on 5 April 2021).

55. Access to Medicine Foundation. Access to Medicine Index; Access to Medicine Foundation: Amsterdam, The Netherlands, $2021 ;$ p. 237.

56. Newman, D.J.; Cragg, G.M. Natural products as sources of new drugs over the nearly four decades from 01/1981 to 09/2019. J. Nat. Prod. 2020, 80, 770-803. [CrossRef]

57. WHO. The Twenty Conditions Identified by WHO as NTDs Are: Buruli Ulcer, Chagas Disease, Dengue and Chikungunya, Dracunculiasis, Echinococcosis, Foodborne Trematodiases, Human African Trypanosomiasis, Leishmaniasis, Leprosy, Lymphatic Filariasis, Myce-Toma, Chromoblastomycosis and Other Deep Mycoses, Onchocerciasis, Rabies, Scabies and Other Ectoparasitoses, Schistosomiasis, Soil-Transmitted Helminthiases, Snakebite Envenoming, Taeniasis and Cysticercosis, Trachoma and Yaws; WHO: Geneva, Switzerland, 2021.

58. World Health Organization. Ending the Neglect to Attain Sustainable Development Goals. A Road Map for Neglected Tropical Diseases 2021-2030; WHO: Geneva, Switzerland, 2020; p. 55.

59. Capela, R.; Moreira, R.; Lopes, F. An overview of drug resistance in protozoal diseases. Int. J. Mol. Sci. 2019, $20,5748$. [CrossRef] [PubMed]

60. Keiser, J. Antimalarials in the treatment of schistosomiasis. Curr. Pharm. Des. 2012, 18, 3531-3538. [CrossRef] [PubMed]

61. Utzinger, J.; Raso, G.; Brooker, S.; De Savigny, D.; Tanner, M.; Ørnbjerg, N.; Singer, B.H.; N'Goran, E.K. Schistosomiasis and neglected tropical diseases: Towards integrated and sustainable control and a word of caution. Parasitology 2009, 136, 1859-1874. [CrossRef] [PubMed]

62. Schafer, T.W.; Hale, B.R. Gastrointestinal complications of schistosomiasis. Curr. Gastroenterol. Rep. 2001, 3, $293-303$. [CrossRef] [PubMed]

63. Cioli, D.; Pica-Mattoccia, L.; Archer, S. Antischistosomal drugs: Past, present ... and future? Pharmacol. Ther. 1995, 68, 35-85. [CrossRef]

64. Utzinger, J.; Shuhua, X.; N'Goran, E.K.; Bergquist, R.; Tanner, M. The potential of artemether for the control of schistosomiasis. Int. J. Parasitol. 2001, 31, 1549-1562. [CrossRef]

65. Coles, G.; Bruce, J.; Kinoti, G.; Mutahi, W.; Dias, L.; Rocha, R.; Katz, N. The potential for drug resistance in schistosomiasis Parasitol. Today 1987, 3, 349-350. [CrossRef]

66. Danso-Appiah, A.; De Vlas, S.J. Interpreting low praziquantel cure rates of Schistosoma mansoni infections in Senegal. Trends Parasitol. 2002, 18, 125-129. [CrossRef]

67. Mostafa, O.M.S.; Eid, R.A.; Adly, M.A. Antischistosomal activity of ginger (Zingiber officinale) against Schistosoma mansoni harbored in C57 mice. Parasitol. Res. 2011, 109, 395-403. [CrossRef]

68. Guimarães, M.A.; De Oliveira, R.N.; Véras, L.M.C.; Lima, D.F.; Campelo, Y.D.M.; Campos, S.A.; Kuckelhaus, S.A.S.; Pinto, P.L.S.; Eaton, P.; Mafud, A.C.; et al. Anthelmintic activity in vivo of epiisopiloturine against juvenile and adult worms of Schistosoma mansoni. PLoS Negl. Trop. Dis. 2015, 9, e0003656. [CrossRef]

69. Chatterjee, A.; Dutta, C.P. Alkaloids of Piper longum Linn. I. Structure and synthesis of piperlongumine and piperlonguminine. Tetrahedron 1967, 23, 1769-1781. [CrossRef]

70. Bezerra, D.P.; Pessoa, C.; de Moraes, M.O.; Saker-Neto, N.; Silveira, E.R.; Costa-Lotufo, L.V. Overview of the therapeutic potential of piplartine (piperlongumine). Eur. J. Pharm. Sci. 2013, 48, 453-463. [CrossRef]

71. De Moraes, J.; Nascimento, C.; Lopes, P.O.M.V.; Nakano, E.; Yamaguchi, L.F.; Kato, M.; Kawano, T. Schistosoma mansoni: In vitro schistosomicidal activity of piplartine. Exp. Parasitol. 2011, 127, 357-364. [CrossRef]

72. Bezerra, D.P.; Militão, G.C.G.; de Castro, F.O.; Pessoa, C.; de Moraes, M.O.; Silveira, E.R.; Lima, M.A.S.; Elmiro, F.J.M.; CostaLotufo, L.V. Piplartine induces inhibition of leukemia cell proliferation triggering both apoptosis and necrosis pathways. Toxicol. Vitr. 2007, 21, 1-8. [CrossRef]

73. De Moraes, J.; Keiser, J.; Ingram, K.; Nascimento, C.; Yamaguchi, L.F.; Bittencourt, C.R.; Bemquerer, M.P.; Leite, J.R.; Kato, M.J.; Nakano, E. In vitro synergistic interaction between amide piplartine and antimicrobial peptide dermaseptin against Schistosoma mansoni schistosomula and adult worms. Curr. Med. Chem. 2013, 20, 301-309. [CrossRef]

74. Bezerra, D.P.; Moura, D.J.; Rosa, R.M.; de Vasconcellos, M.C.; Silva, A.C.R.; de Moraes, M.O.; Silveira, E.R.; Lima, M.A.; Henriques, J.A.; Costa-Lotufo, L.V.; et al. Evaluation of the genotoxicity of piplartine, an alkamide of Piper tuberculatum, in yeast and mammalian V79 cells. Mutat. Res. Genet. Toxicol. Environ. Mutagen. 2008, 652, 164-174. [CrossRef]

75. Schaab, E.H.; Crotti, A.E.M.; Iamamoto, Y.; Kato, M.; Lotufo, L.V.C.; Lopes, N.P. Biomimetic oxidation of piperine and piplartine catalyzed by iron(III) and manganese(III) porphyrins. Biol. Pharm. Bull. 2010, 33, 912-916. [CrossRef]

76. Raj, L.; Ide, T.; Gurkar, A.U.; Foley, M.A.; Schenone, M.; Li, X.; Tolliday, N.J.; Golub, T.R.; Carr, S.A.; Shamji, A.F.; et al. Selective killing of cancer cells by a small molecule targeting the stress response to ROS. Nat. Cell Biol. 2011, 475, 231-234. [CrossRef]

77. Prasad, K.B.; Reddy, G.A.K.; Joy, J.M.; Rasheed, A.; Dalith, D. Natural antifilarial drugs: A review. Int. J. Pharmacol. Toxicol. 2011, $1,1-10$. 
78. Bulman, C.A.; Bidlow, C.M.; Lustigman, S.; Cho-Ngwa, F.; Williams, D.; Rascón, J.A.A.; Tricoche, N.; Samje, M.; Bell, A.; Suzuki, B.; et al. Repurposing auranofin as a lead candidate for treatment of lymphatic filariasis and onchocerciasis. PLoS Negl. Trop. Dis. 2015, 9, e0003534. [CrossRef]

79. Wei, G.; Wei, D.; Du, Y. An alternative total synthesis of solamargine. Sci. China Ser. B Chem. 2012, 55, 1247-1251. [CrossRef]

80. Murray, H.W.; Berman, J.D.; Davies, C.R.; Saravia, N.G. Advances in leishmaniasis. Lancet 2005, 366, 1561-1577. [CrossRef]

81. Amato, V.S.; Tuon, F.F.; Bacha, H.A.; Neto, V.A.; Nicodemo, A.C. Mucosal leishmaniasis. Acta Trop. 2008, 105, 1-9. [CrossRef] [PubMed]

82. Singh, R.K.; Pandey, H.P.; Sundar, S. Visceral leishmaniasis (kala-azar): Challenges ahead. Indian J. Med Res. 2006, 123, 331-344. [PubMed]

83. Cheuka, P.M.; Mayoka, G.; Mutai, P.; Chibale, K. The role of natural products in drug discovery and development against neglected tropical diseases. Molecules 2016, 22, 58. [CrossRef]

84. Hughes, D.; Andersson, D.I. Evolutionary consequences of drug resistance: Shared principles across diverse targets and or-ganisms. Nat. Rev. Genet. 2015, 16, 459-471. [CrossRef]

85. Dadgostar, P. Antimicrobial resistance: Implications and costs. Infect. Drug Resist. 2019, 12, 3903-3910. [CrossRef]

86. Nathan, C.; Cars, O. Antibiotic resistance-problems, progress, and prospects. N. Engl. J. Med. 2014, 371, 1761-1763. [CrossRef]

87. Wohlleben, W.; Mast, Y.; Stegmann, E.; Ziemert, N. Antibiotic drug discovery. Microb. Biotechnol. 2016, 9, 541-548. [CrossRef]

88. Brown, E.D.; Wright, G.D. Antibacterial drug discovery in the resistance era. Nature 2016, 529, 336-343. [CrossRef]

89. Wright, G.D. Opportunities for natural products in 21st century antibiotic discovery. Nat. Prod. Rep. 2017, 34, 694-701. [CrossRef]

90. Bhattarai, K.; Bastola, R.; Baral, B. Antibiotic drug discovery: Challenges and perspectives in the light of emerging antibiotic resistance. Adv. Genet. 2020, 105, 229-292. [CrossRef]

91. Kraus, C.N. Low hanging fruit in infectious disease drug development. Curr. Opin. Microbiol. 2008, 11, 434-438. [CrossRef]

92. Butler, M.S.; Buss, A.D. Natural products-The future scaffolds for novel antibiotics? Biochem. Pharmacol. 2006, 71, 919-929. [CrossRef]

93. Rice, L.B. Federal funding for the study of antimicrobial resistance in nosocomial pathogens: No ESKAPE. J. Infect. Dis. 2008, 197, 1079-1081. [CrossRef]

94. Mulani, M.S.; Kamble, E.; Kumkar, S.N.; Tawre, M.S.; Pardesi, K.R. Emerging strategies to combat ESKAPE pathogens in the era of antimicrobial resistance: A review. Front. Microbiol. 2019, 10, 539. [CrossRef]

95. Centers for Disease Control and Prevention (CDC). Antibiotic Resistance Threats in the United States, Atlanta, GA, CDC. 2019. Available online: https://www.cdc.gov/drugresistance/index.html (accessed on 5 April 2021).

96. Butaye, P.; Devriese, L.A.; Haesebrouck, F. Antimicrobial growth promoters used in animal feed: Effects of less well-known antibiotics on Gram-positive bacteria. Clin. Microbiol. Rev. 2003, 16, 175-188. [CrossRef]

97. Casewell, M.; Friis, C.; Marco, E.; McMullin, P.; Phillips, I. The European ban on growth-promoting antibiotics and emerging consequences for human and animal health. J. Antimicrob. Chemother. 2003, 52, 159-161. [CrossRef]

98. Drawz, S.M.; Papp-Wallace, K.M.; Bonomo, R.A. New $\beta$-lactamase inhibitors: A therapeutic renaissance in an MDR world. Antimicrob. Agents Chemother. 2014, 58, 1835-1846. [CrossRef]

99. Bueno, J. Antimicrobial adjuvants drug discovery, the challenge of avoid the resistance and recover the susceptibility of multidrug-resistant strains. J. Microb. Biochem. Technol. 2016, 8, 169-176. [CrossRef]

100. Viveiros, M.; Amaral, L. Enhancement of antibiotic activity against polydrug resistant Mycobacterium tuberculosis by phenothiazines. Int. J. Antimicrob. Agents 2001, 17, 225-228. [CrossRef]

101. Dastidar, S.G.; Kristiansen, J.E.; Molnar, J.; Amaral, L. Role of phenothiazines and structurally similar compounds of plant origin in the fight against infections by drug resistant bacteria. Antibiotics 2013, 2, 58-72. [CrossRef]

102. Tang, J.; Feng, Y.; Tsao, S.; Wang, N.; Curtain, R.; Wang, Y. Berberine and Coptidis Rhizoma as novel antineoplastic agents: A review of traditional use and biomedical investigations. J. Ethnopharmacol. 2009, 126, 5-17. [CrossRef]

103. Tillhon, M.; Ortiz, L.M.G.; Lombardi, P.; Scovassi, A.I. Berberine: New perspectives for old remedies. Biochem. Pharmacol. 2012, 84, 1260-1267. [CrossRef]

104. Imenshahidi, M.; Hosseinzadeh, H. Berberis vulgaris and berberine: An update review. Phytother. Res. 2016, 30, 1745-1764. [CrossRef]

105. Gao, Y.; Wang, F.; Song, Y.; Liu, H. The status of and trends in the pharmacology of berberine: A bibliometric review [1985-2018]. Chin. Med. 2020, 15, 1-13. [CrossRef]

106. Sun, T.; Li, X.-D.; Hong, J.; Liu, C.; Zhang, X.-L.; Zheng, J.-P.; Xu, Y.-J.; Ou, Z.-Y.; Zheng, J.-L.; Yu, D.-J. Inhibitory effect of two traditional Chinese medicine monomers, berberine and matrine, on the quorum sensing system of antimicrobial-resistant Escherichia coli. Front. Microbiol. 2019, 10, 2584. [CrossRef]

107. Yu, H.-H.; Kim, K.-J.; Cha, J.-D.; Kim, H.-K.; Lee, Y.-E.; Choi, N.-Y.; You, Y.O. Antimicrobial activity of berberine alone and in combination with ampicillin or oxacillin against methicillin-resistant Staphylococcus aureus. J. Med. Food 2005, 8, $454-461$. [CrossRef] [PubMed]

108. Habtemariam, S. Berberine and inflammatory bowel disease: A concise review. Pharmacol. Res. 2016, 113, 592-599. [CrossRef] [PubMed]

109. Yu, M.; Jin, X.; Liang, C.; Bu, F.; Pan, D.; He, Q.; Ming, Y.; Little, P.; Du, H.; Liang, S.; et al. Berberine for diarrhea in children and adults: A systematic review and meta-analysis. Ther. Adv. Gastroenterol. 2020, 13, 1756284820961299. [CrossRef] [PubMed] 
110. Dai, J.; Yang, L.X.; Jamshaid, F. New development of novel berberine derivatives against bacteria. Mini Rev. Med. Chem. 2020, 20, 716-724. [CrossRef]

111. Kim, J.H.; Ryu, Y.B.; Lee, W.S.; Kim, Y.H. Neuraminidase inhibitory activities of quaternary isoquinoline alkaloids from Co-rydalis turtschaninovii rhizome. Bioorg. Med. Chem. 2014, 22, 604-6052. [CrossRef]

112. Cascioferro, S.; Totsika, M.; Schillaci, D. Sortase A: An ideal target for anti-virulence drug development. Microb. Pathog. 2014, 77, 105-112. [CrossRef]

113. Guan, G.; Wang, H. The anticancer effect of sanguinarine: A review. Curr. Pharm. Des. 2018, 24, 2760-2764. [CrossRef]

114. Godowski, K.C. Antimicrobial action of sanguinarine. J. Clin. Dent. 1989, 1, 96-101.

115. Wennström, J.; Lindhe, J. Some effects of a sanguinarine-containing mouth rinse on developing plaque and gingivitis. J. Clin. Periodont. 1985, 12, 867-872. [CrossRef]

116. Zhong, H.; Hu, D.-D.; Hu, G.-H.; Su, J.; Bi, S.; Zhang, Z.-E.; Wang, Z.; Zhang, R.-L.; Xu, Z.; Jiang, Y.-Y.; et al. Activity of sanguinarine against Candida albicans biofilms. Antimicrob. Agents Chemother. 2017, 61, e02259-e02316. [CrossRef]

117. Yao, J.-Y.; Shen, J.-Y.; Li, X.-L.; Xu, Y.; Hao, G.-J.; Pan, X.-Y.; Wang, G.-X.; Yin, W.-L. Effect of sanguinarine from the leaves of Macleaya cordata against Ichthyophthirius multifiliis in grass carp (Ctenopharyngodon idella). Parasitol. Res. 2010, 107, 1035-1042. [CrossRef]

118. Yang, X.-J.; Miao, F.; Yao, Y.; Cao, F.-J.; Yang, R.; Ma, Y.-N.; Qin, B.-F.; Zhou, L. In vitro antifungal activity of sanguinarine and chelerythrine derivatives against phytopathogenic fungi. Molecules 2012, 17, 13026-13035. [CrossRef]

119. Zhang, S.-M.; Coultas, K.A. Identification of plumbagin and sanguinarine as effective chemotherapeutic agents for treatment of schistosomiasis. Int. J. Parasitol. Drugs Drug Resist. 2013, 3, 28-34. [CrossRef]

120. Meng, L.-H.; Li, X.-M.; Liu, Y.; Wang, B.-G. Polyoxygenated dihydropyrano[2,3-c]pyrrole-4,5-dione derivatives from the marine mangrove-derived endophytic fungus Penicillium brocae MA-231 and their antimicrobial activity. Chin. Chem. Lett. 2015, 26, 610-612. [CrossRef]

121. Bontemps, N.; Bry, D.; López-Legentil, S.; Simon-Levert, A.; Long, C.; Banaigs, B. Structures and antimicrobial activities of pyridoacridine alkaloids isolated from different chromotypes of the ascidian Cystodytes dellechiajei. J. Nat. Prod. 2010, 73, 1044-1048. [CrossRef]

122. Won, T.H.; Jeon, J.-E.; Lee, S.-H.; Rho, B.J.; Oh, K.-B.; Shin, J. Beta-carboline alkaloids derived from the ascidian Synoicum sp. Bioorg. Med. Chem. 2012, 20, 4082-4087. [CrossRef]

123. Moore, K.S.; Wehrli, S.; Roder, H.; Rogers, M.; Forrest, J.N.; McCrimmon, D.; Zasloff, M. Squalamine: An aminosterol antibiotic from the shark. Proc. Natl. Acad. Sci. USA 1993, 90, 1354-1358. [CrossRef]

124. Alhanout, K.; Malesinki, S.; Vidal, N.; Peyrot, V.; Rolain, J.M.; Brunel, J.M. New insights into the antibacterial mechanism of action of squalamine. J. Antimicrob. Chemother. 2010, 65, 1688-1693. [CrossRef]

125. Alves, R.R.N.; Rosa, I.M.L. Biodiversity, traditional medicine and public health: Where do they meet? J. Ethnobiol. Ethnomed. 2007, 3, 1-9. [CrossRef]

126. Alkemade, R.; Reid, R.S.; van den Berg, M.; de Leeuw, J.; Jeuken, M. Assessing the impacts of livestock production on biodi-versity in rangeland ecosystems. Proc. Natl. Acad. Sci. USA 2013, 110, 20900-20905. [CrossRef] [PubMed]

127. Sánchez-Cuervo, A.M.; de Lima, L.S.; Dallmeier, F.; Garate, P.; Bravo, A.; Vanthomme, H. Twenty years of land cover change in the southeastern Peruvian Amazon: Implications for biodiversity conservation. Reg. Environ. Chang. 2020, 20, 1-14. [CrossRef]

128. Cordell, G.A. Biodiversity and drug discovery-A symbiotic relationship. Phytochemistry 2000, 55, 463-480. [CrossRef]

129. Cordell, G.A. Ecopharmacognosy and the responsibilities of natural product research to sustainability. Phytochem. Lett. 2015, 11, 332-346. [CrossRef]

130. Cordell, G.A. Cognate and cognitive ecopharmacognosy-In an anthropogenic era. Phytochem. Lett. 2017, 20, 540-549. [CrossRef]

131. Winnikoff, J.R.; Glukhov, E.; Watrous, J.; Dorrestein, P.C.; Gerwick, W.H. Quantitative molecular networking to profile marine cyanobacterial metabolomes. J. Antibiot. 2014, 67, 105-112. [CrossRef]

132. Wu, H.-Y.; Ke, J.-P.; Wang, W.; Kong, Y.-S.; Zhang, P.; Ling, T.-J.; Bao, G.-H. Discovery of neolignan glycosides with acetylcholinesterase inhibitory activity from Huanginya green tea guided by ultra-performance liquid chromatography-tandem mass spectrometry data and Global Natural Product Social molecular networking. J. Agric. Food Chem. 2019, 67, 11986-11993. [CrossRef]

133. Corley, D.G.; Durley, R.C. Strategies for database dereplication of natural products. J. Nat. Prod. 1994, 57, 1484-1490. [CrossRef]

134. Hubert, J.; Nuzillard, J.-M.; Renault, J.-H. Dereplication strategies in natural product research: How many tools and methodologies behind the same concept? Phytochem. Rev. 2017, 16, 55-95. [CrossRef]

135. Wolfender, J.-L.; Marti, G.; Queiroz, E.F. Advances in techniques for profiling crude extracts and for the rapid identification of natural products: Dereplication, quality control and metabolomics. Curr. Org. Chem. 2010, 14, 1808-1832. [CrossRef]

136. Yuliana, N.D.; Jahangir, M.; Verpoorte, R.; Choi, Y.H. Metabolomics for the rapid dereplication of bioactive compounds from natural sources. Phytochem. Rev. 2013, 12, 293-304. [CrossRef]

137. Pérez-Victoria, I.; Martín, J.; Reyes, F. Combined LC/UV/MS and NMR strategies for the dereplication of marine natural products. Planta Med. 2016, 82, 857-871. [CrossRef]

138. Allard, P.-M.; Péresse, T.; Bisson, J.; Gindro, K.; Marcourt, L.; Pham, V.C.; Roussi, F.; Litaudon, M.; Wolfender, J.-L. Integration of molecular networking and in-silico MS/MS fragmentation for natural products dereplication. Anal. Chem. 2016, 88, 3317-3323. [CrossRef] 
139. Cordell, G.A.; Beecher, C.W.W.; Kinghorn, A.D.; Pezzuto, J.M.; Constant, H.L.; Fang, L.; Seo, E.-K.; Long, L.; Cui, B.-L.; Barrilos, K.S. The dereplication of natural products. In Studies in Natural Products Chemistry; Atta-ur-Rahman, Ed.; Elsevier Science Publishers: Amsterdam, The Netherlands, 1997; Volume 19, pp. 749-791.

140. Cordell, G.A.; Shin, Y.G. Finding the needle in the haystack. The dereplication of natural product extracts. Pure Appl. Chem. 1999, 71, 1089-1094. [CrossRef]

141. Baell, J.B. Feeling nature's PAINS: Natural products, natural product drugs, and pan assay interference compounds (PAINS). J. Nat. Prod. 2016, 79, 616-628. [CrossRef]

142. Baell, J.B.; Holloway, G.A. New substructure filters for removal of pan assay interference compounds (PAINS) from screening libraries and for their exclusion in bioassays. J. Med. Chem. 2010, 53, 2719-2740. [CrossRef] [PubMed]

143. Bisson, J.; McAlpine, J.B.; Friesen, J.B.; Chen, S.-N.; Graham, J.; Pauli, G.F. Can invalid bioactives undermine natural product-based drug discovery? J. Med. Chem. 2016, 59, 1671-1690. [CrossRef] [PubMed]

144. Powell, R.G.; Smith, C.R., Jr.; Weisleder, D.; Muthard, D.A.; Clardy, J. Sesbanine, a novel cytotoxic alkaloid from Sesbania drummondii. J. Am. Chem. Soc. 1979, 101, 2784-2785. [CrossRef]

145. Powell, R.G.; Smith, C.R.; Weisleder, D.; Matsumoto, G.; Clardy, J.; Kozlowski, J. Sesbanimide, a potent antitumor substance from Sesbania drummondii seed. J. Am. Chem. Soc. 1983, 105, 3739-3741. [CrossRef]

146. Choules, M.P.; Klein, L.L.; Lankin, D.C.; McAlpine, J.B.; Cho, S.-H.; Cheng, J.; Lee, H.; Suh, J.-W.; Jaki, B.U.; Franzblau, S.G.; et al. Residual complexity does impact organic chemistry and drug discovery: The case of rufomyazine and rufomycin. J. Org. Chem. 2018, 83, 6664-6672. [CrossRef]

147. Jaki, B.U.; Franzblau, S.; Chadwick, L.R.; Lankin, D.C.; Zhang, F.; Wang, Y.; Pauli, G. Purity-activity relationships of natural products: The case of anti-TB active ursolic acid. J. Nat. Prod. 2008, 71, 1742-1748. [CrossRef]

148. Nwaka, S.; Ridley, R.G. Virtual drug discovery and development for neglected diseases through public-private partnerships. Nat. Rev. Drug Discov. 2003, 2, 919-928. [CrossRef]

149. Ioset, J.-R.; Chatelain, E. Drug discovery and development for neglected diseases: The DNDi model. Drug Des. Dev. Ther. 2011, 5, 175-181. [CrossRef]

150. Johnston, K.L.; Ford, L.; Taylor, M.J. Overcoming the challenges of drug discovery for neglected tropical diseases: The A.WOL experience. J. Biomol. Screen. 2014, 19, 335-343. [CrossRef]

151. Sunyoto, T. Partnerships for better neglected disease drug discovery and development: How have we fared? Expert Opin. Drug Discov. 2020, 15, 531-537. [CrossRef]

152. Simpkin, V.L.; Renwick, M.J.; Kelly, R.; Mossialos, E. Incentivising innovation in antibiotic drug discovery and development: Progress, challenges and next steps. J. Antibiot. 2017, 70, 1087-1096. [CrossRef]

153. Reed, J.C.; White, E.L.; Aube, J.; Lindsley, C.; Li, M.; Sklar, L.; Schreiber, S. The NIH's role in accelerating translational sciences. Nat. Biotechnol. 2012, 30, 16-19. [CrossRef]

154. Jarvis, L.M. NIH initiative aims to partner academics with pharmaceutical companies to revive failed drug candidates. Chem. Eng. News 2012, 90, 41-43.

155. Roberts, J.P. Incentives aim to boost antibiotic development. Nat. Biotechnol. 2012, 30, 735. [CrossRef]

156. Tralau-Stewart, C.J.; Wyatt, C.A.; Kleyn, D.E.; Ayad, A. Drug discovery: New models for industry-academic partnerships. Drug Discov. Today 2009, 14, 95-101. [CrossRef]

157. Cragg, G.M.; Newman, A.D.J.; Snader, K.M. Natural products in drug discovery and development. J. Nat. Prod. 1997, 60, 52-60. [CrossRef]

158. Light, D.W. Addressing health care disparities: A radical perspective and proposal. Front. Sociol. 2020, 5, 29. [CrossRef]

159. Zicker, F.; Faid, M.; Reeder, J.; Aslanyan, G. Building coherence and synergy among global health initiatives. Health Res. Policy Syst. 2015, 13, 1-8. [CrossRef]

160. Young, R.; Bekele, T.; Gunn, A.; Chapman, N.; Chowdhary, V.; Corrigan, K.; Dahora, L.; Martinez, S.; Permar, S.; Persson, J.; et al. Developing new health technologies for neglected diseases: A pipeline portfolio review and cost model. Gates Open Res. 2018, 2, 23. [CrossRef]

161. Lagunin, A.A.; Goel, R.; Gawande, D.; Pahwa, P.; Gloriozova, T.A.; Dmitriev, A.; Ivanov, S.; Rudik, A.V.; Konova, V.I.; Pogodin, P.V.; et al. Chemo- and bioinformatics resources for in silico drug discovery from medicinal plants beyond their traditional use: A critical review. Nat. Prod. Rep. 2014, 31, 1585-1611. [CrossRef]

162. Olğaç, A.; Orhan, I.E.; Banoglu, E. The potential role of in silico approaches to identify novel bioactive molecules from natural resources. Future Med. Chem. 2017, 9, 1665-1686. [CrossRef]

163. Park, K. A review of computational drug repurposing. Transl. Clin. Pharmacol. 2019, 27, 59-63. [CrossRef]

164. Scotti, L.; Ishiki, H.; Mendonça, F.; Silva, M.; Scotti, M. In-silico analyses of natural products on leishmania enzyme targets. Mini Rev. Med. Chem. 2015, 15, 253-269. [CrossRef]

165. Argüelles, A.J.; Cordell, G.A.; Maruenda, H. Molecular docking and binding mode analysis of plant alkaloids as in vitro and in silico inhibitors of trypanothione reductase from Trypanosoma cruzi. Nat. Prod. Commun. 2016, 11, 57-62. [CrossRef]

166. Sobarzo-Sánchez, E.; Bilbao-Ramos, P.; Dea-Ayuela, M.; González-Díaz, H.; Yañez, M.; Uriarte, E.; Santana, L.; MartínezSernández, V.; Bolás-Fernández, F.; Ubeira, F.M. Synthetic oxoisoaporphine alkaloids: In vitro, in vivo and in silico assessment of antileishmanial activities. PLoS ONE 2013, 8, e77560. [CrossRef] 
167. Powers, C.N.; Setzer, W.N. An in-silico investigation of phytochemicals as antiviral agents against dengue fever. Comb. Chem. High Throughput Screen. 2016, 19, 516-536. [CrossRef]

168. Behera, D.R.; Bhatnagar, S. In vitro and in silico efficacy of isolated alkaloid compounds from Rauvolfia tetraphylla L. against bovine filarial parasite Setaria cervi: A drug discovery approach. J. Parasit. Dis. 2019, 43, 103-112. [CrossRef]

169. Casciaro, B.; Calcaterra, A.; Cappiello, F.; Mori, M.; Loffredo, M.R.; Ghirga, F.; Mangoni, M.L.; Botta, B.; Quaglio, D. Nigritanine as a new potential antimicrobial alkaloid for the treatment of Staphylococcus aureus-induced infections. Toxins 2019, 11, 511. [CrossRef]

170. Laudadio, E.; Cedraro, N.; Mangiaterra, G.; Citterio, B.; Mobbili, G.; Minnelli, C.; Bizzaro, D.; Biavasco, F.; Galeazzi, R. Natural alkaloid berberine activity against Pseudomonas aeruginosa MexXY-mediated aminoglycoside resistance: In silico and in vitro studies. J. Nat. Prod. 2019, 82, 1935-1944. [CrossRef] [PubMed]

171. Dwivedi, G.R.; Maurya, A.; Yadav, D.K.; Singh, V.; Khan, F.; Gupta, M.K.; Singh, M.; Darokar, M.P.; Srivastava, S.K. Synergy of clavine alkaloid 'chanoclavine' with tetracycline against multi-drug-resistant E. coli. J. Biomol. Struct. Dyn. 2019, 37, 1307-1325. [CrossRef] [PubMed]

172. Annunziato, G. Strategies to overcome antimicrobial resistance (AMR) making use of non-essential target inhibitors: A review. Int. J. Mol. Sci. 2019, 20, 5844. [CrossRef]

173. Shiraishi, N.; Akiyama, S.-i.; Nakagawa, M.; Kobayashi, M.; Kuwano, M. Effect of bisbenzylisoquinoline (bis-coclaurine) alkaloids on multidrug resistance in KB human cancer cells. Cancer Res. 1987, 47, 2413-2416.

174. Nakajima, A.; Yamamoto, Y.; Taura, K.; Hata, K.; Fukumoto, M.; Uchinami, H.; Yonezawa, K.; Yamaoka, Y. Beneficial effect of cepharanthine on overcoming drug-resistance of hepatocellular carcinoma. Int. J. Oncol. 2004, 24, 635-645. [CrossRef]

175. Xu, W.; Chen, S.; Wang, X.; Wu, H.; Yamada, H.; Hirano, T. Bisbenzylisoquinoline alkaloids and P-glycoprotein function: A structure activity relationship study. Bioorg. Med. Chem. 2020, 28, 115553. [CrossRef]

176. Saifah, E.; Puripattanavong, J.; Likhitwitayawuid, K.; Cordell, G.A.; Chai, H.; Pezzuto, J.M. Bisamides from Aglaia species: Structure analysis and potential to reverse drug resistance with cultured cells. J. Nat. Prod. 1993, 56, 473-477. [CrossRef]

177. You, M.; Ma, X.-J.; Mukherjee, R.; Farnsworth, N.R.; Cordell, G.A.; Kinghorn, A.D.; Pezzuto, J.M. Indole alkaloids from Peschiera laeta that enhance vinblastine-mediated cytotoxicity with multidrug-resistant cells. J. Nat. Prod. 1994, 57, 1517-1522. [CrossRef]

178. You, M.; Wickramaratne, D.B.M.; Silva, G.L.; Chai, H.; Chagwedera, T.E.; Farnsworth, N.R.; Cordell, G.A.; Kinghorn, A.D.; Pezzuto, J.M. (-)-Roemerine, an aporphine alkaloid from Annona senegalensis that reverses the multidrug-resistance phenotype with cultured cells. J. Nat. Prod. 1995, 58, 598-604. [CrossRef]

179. Silva, G.L.; Cui, B.; Chávez, D.; You, M.; Chai, H.B.; Rasoanaivo, P.; Lynn, S.M.; O’Neill, M.J.; Lewis, J.A.; Besterman, J.M.; et al. Modulation of the multidrug-resistance phenotype by new tropane alkaloid aromatic esters from Erythroxylum pervillei. J. Nat. Prod. 2001, 64, 1514-1520. [CrossRef]

180. Baumert, C.; Hilgeroth, A. Recent advances in the development of P-gp inhibitors. Anticancer Agents Med. Chem. 2009, 9, 415-436. [CrossRef]

181. Huang, X.-C.; Xiao, X.; Zhang, Y.-K.; Talele, T.T.; Salim, A.A.; Chen, Z.-S.; Capon, R.J. Lamellarin O, a pyrrole alkaloid from an Australian marine sponge, Ianthella sp., reverses BCRP mediated drug resistance in cancer cells. Mar. Drugs 2014, 12, 3818-3837. [CrossRef]

182. Wang, Y.-P.; Zhao, W.; Xue, R.; Zhou, Z.-X.; Liu, F.; Han, Y.-X.; Ren, G.; Peng, Z.-G.; Cen, S.; Chen, H.-S.; et al. Oxymatrine inhibits hepatitis B infection with an advantage of overcoming drug-resistance. Antivir. Res. 2011, 89, 227-231. [CrossRef] [PubMed]

183. Frisoni, P.; Bacchio, E.; Bilel, S.; Talarico, A.; Gaudio, R.M.; Barbieri, M.; Neri, M.; Marti, M. Novel synthetic opioids: The pathologist's point of view. Brain Sci. 2018, 8, 170. [CrossRef] [PubMed]

184. Salle, S.; Bodeau, S.; Dhersin, A.; Ferdonnet, M.; Goncalves, R.; Lenski, M.; Lima, B.; Martin, M.; Outreville, J.; Vaucel, J.; et al. Novel synthetic opioids: A review of the literature. Toxicol. Anal. Clin. 2019, 31, 298-316. [CrossRef]

185. Kyzer, J.L.; Wenthur, C.J. Classics in chemical neuroscience: Buprenorphine. ACS Chem. Neurosci. 2020, 11, 1385-1399. [CrossRef] [PubMed]

186. Hamilton-Miller, J. Development of the semi-synthetic penicillins and cephalosporins. Int. J. Antimicrob. Agents 2008, 31, 189-192. [CrossRef]

187. Etebu, E.; Arikekpar, I. Antibiotics: Classification and mechanisms of action with emphasis on molecular perspectives. Int. J. Appl. Microbiol. Biotechnol. Res. 2016, 4, 90-101.

188. Kennedy, J.P.; Williams, L.; Bridges, T.M.; Daniels, R.N.; Weaver, D.; Lindsley, C.W. Application of combinatorial chemistry science on modern drug discovery. J. Comb. Chem. 2008, 10, 345-354. [CrossRef]

189. Kolb, H.C.; Sharpless, K.B. The growing impact of click chemistry on drug discovery. Drug Discov. Today 2003, 8, 1128-1137. [CrossRef]

190. Lombardino, J.G.; Lowe, J.A. The role of the medicinal chemist in drug discovery-Then and now. Nat. Rev. Drug Discov. 2004, 3, 853-862. [CrossRef]

191. Hou, J.; Liu, X.; Shen, J.; Zhao, G.; Wang, P.G. The impact of click chemistry in medicinal chemistry. Expert Opin. Drug Discov. 2012, 7, 489-501. [CrossRef]

192. Jiang, X.; Hao, X.; Jing, L.; Wu, G.; Kang, D.; Liu, X.; Zhan, P. Recent applications of click chemistry in drug discovery. Expert Opin. Drug Discov. 2019, 14, 779-789. [CrossRef]

193. Cordell, G.A. Natural products in drug discovery-Creating a new vision. Phytochem. Rev. 2002, 1, 261-273. [CrossRef] 
194. Ramallo, I.A.; Salazar, M.O.; Méndez, L.; Furlán, R.L.E. Chemically engineered extracts: Source of bioactive compounds. Accounts Chem. Res. 2011, 44, 241-250. [CrossRef]

195. Ramallo, I.A.; Alonso, V.L.; Rua, F.; Serra, E.; Furlán, R.L.E. A bioactive Trypanosoma cruzi bromodomain inhibitor from chemically engineered extracts. ACS Comb. Sci. 2018, 20, 220-228. [CrossRef]

196. Du, Y.; Sun, J.; Gong, Q.; Wang, Y.; Fu, P.; Zhu, W. New $\alpha$-pyridones with quorum-sensing inhibitory activity from diversityenhanced extracts of a Streptomyces sp. derived from marine algae. J. Agric. Food Chem. 2018, 66, 1807-1812. [CrossRef]

197. Salazar, M.O.; Osella, M.I.; Arcusin, D.E.J.; Lescano, L.E.; Furlan, R.L.E. New $\alpha$-glucosidase inhibitors from a chemically en-gineered essential oil of Origanum vulgare L. Ind. Crop. Prod. 2020, 156, 112855. [CrossRef]

198. Tomohara, K.; Ito, T.; Furusawa, K.; Hasegawa, N.; Tsuge, K.; Kato, A.; Adachi, I. Multiple production of $\alpha$, $\alpha$-disubstituted amino acid derivatives through direct chemical derivatization of natural plant extracts: An apparently difficult but successful route. Tetrahedron Lett. 2017, 58, 3143-3147. [CrossRef]

199. Kamauchi, H.; Noji, M.; Kinoshita, K.; Takanami, T.; Koyama, K. Coumarins with an unprecedented tetracyclic skeleton and coumarin dimers from chemically engineered extracts of a marine-derived fungus. Tetrahedron 2018, 74, 2846-2856. [CrossRef]

200. Zhang, J.-L.; Xu, W.; Zhou, Z.-R.; Li, J.; Jiang, L.-L.; Zhang, X.-X.; Jiang, R.-W. Antineoplastic constituents from the chemical diversified extract of Radix puerariae. Chem. Biodivers. 2019, 16, e1800408. [CrossRef]

201. Hogg, J.A. Steroids, the steroid community, and Upjohn in perspective: A profile of innovation. Steroids 1992, 57, 593-616. [CrossRef]

202. Rathbone, D.A.; Lister, D.L.; Bruce, N.C. Biotransformation of alkaloids. In The Alkaloids: Chemistry and Biology; Elsevier BV: Amsterdam, The Netherlands, 2001; Volume 57, pp. 1-74.

203. Rathbone, D.A.; Bruce, N.C. Microbial transformation of alkaloids. Curr. Opin. Microbiol. 2002, 5, 274-281. [CrossRef]

204. Boonstra, B.; Rathbone, D.A.; French, C.E.; Walker, E.H.; Bruce, N.C. cofactor regeneration by a soluble pyridine nucleotide transhydrogenase for biological production of hydromorphone. Appl. Environ. Microbiol. 2000, 66, 5161-5166. [CrossRef]

205. Boonstra, B.; Rathbone, D.A.; Bruce, N.C. Engineering novel biocatalytic routes for production of semisynthetic opiate drugs. Biomol. Eng. 2001, 18, 41-47. [CrossRef]

206. Kiener, A.; Roduit, J.-P.; Wellig, A. Renewable functionalized pyridines derived from microbial metabolites of the alkaloid (S)-nicotine. Heterocycles 1997, 45, 1687. [CrossRef]

207. Baitsch, D.; Sandu, C.; Brandsch, R.; Igloi, G.L. Gene cluster on pAO1 of Arthrobacter nicotinovorans involved in degradation of the plant alkaloid nicotine: Cloning, purification, and characterization of 2,6-dihydroxypyridine 3-hydroxylase. J. Bacteriol. 2001, 183, 5262-5267. [CrossRef] [PubMed]

208. Brown, S.; Clastre, M.; Courdavault, V.; O'Connor, S.E. De novo production of the plant-derived alkaloid strictosidine in yeast. Proc. Natl. Acad. Sci. USA 2015, 112, 3205-3210. [CrossRef] [PubMed]

209. Fossati, E.; Ekins, A.; Narcross, L.; Zhu, Y.; Falgueyret, J.-P.; Beaudoin, G.A.W.; Facchini, P.J.; Martin, V.J.J. Reconstitution of a 10-gene pathway for synthesis of the plant alkaloid dihydrosanguinarine in Saccharomyces cerevisiae. Nat. Commun. 2014, 5, 3283. [CrossRef] [PubMed]

210. Courdavault, V.; O'Connor, S.E.; Oudin, A.; Besseau, S.; Papon, N. Towards the microbial production of plant-derived anticancer drugs. Trends Cancer 2020, 6, 444-448. [CrossRef] [PubMed]

211. Reetz, M.T. Biocatalysis in organic chemistry and biotechnology: Past, present, and future. J. Am. Chem. Soc. 2013, 135, 12480-12496. [CrossRef]

212. Rosenthaler, L. Durch Enzyme bewirkte asymmetrische Synthesen. Biochem. Z. 1908, 14, $238-253$.

213. Sheldon, R.A.; Woodley, J.M. Role of biocatalysis in sustainable chemistry. Chem. Rev. 2018, 118, 801-838. [CrossRef]

214. Kiss, G.; Celebi-Olçüm, N.; Moretti, R.; Baker, D.; Houk, K.N. Computational enzyme design. Angew. Chem. Int. Ed. 2013, 52, 5700-5725. [CrossRef]

215. Wallace, S.; Balskus, E.P. Opportunities for merging chemical and biological synthesis. Curr. Opin. Biotechnol. 2014, 30, 1-8. [CrossRef]

216. Galanie, S.; Entwistle, D.; Lalonde, J. Engineering biosynthetic enzymes for industrial natural product synthesis. Nat. Prod. Rep. 2020, 37, 1122-1143. [CrossRef]

217. Hyster, T.K.; Knörr, L.; Ward, T.R.; Rovis, T. Biotinylated Rh(III) complexes in engineered streptavidin for accelerated asym-metric C-H activation. Science 2012, 338, 500-503. [CrossRef]

218. Liu, L.; Zheng, J.; Zhang, X.; Wang, Z. Interfacing a phosphate catalytic reaction with a microbial metabolism for the production of azaphilone alkaloids. React. Chem. Eng. 2020, 5, 2048-2052. [CrossRef]

219. Turner, N.J.; O'Reilly, E. Biocatalytic retrosynthesis. Nat. Chem. Biol. 2013, 9, 285-288. [CrossRef]

220. Cordell, G.A.; Lemos, T.L.G.; Monte, F.J.Q.; De Mattos, M.C. Vegetables as chemical reagents. J. Nat. Prod. 2007, 70, 478-492. [CrossRef]

221. Xu, B.; Watkins, R.; Wu, L.; Zhang, C.; Davis, R. Natural product-based nanomedicine: Recent advances and issues. Int. J. Nanomed. 2015, 10, 6055-6074. [CrossRef]

222. Kralova, K.; Jampilek, J. Responses of medicinal and aromatic plants to engineered nanoparticles. Appl. Sci. 2021, 11, 1813. [CrossRef]

223. Karakaş, Ö. Effect of silver nanoparticles on production of indole alkaloids in Isatis constricta. Iran. J. Sci. Technol. Trans. A Sci. 2020, 44, 621-627. [CrossRef] 
224. Sahibzada, M.U.K.; Sadiq, A.; Faidah, H.S.; Khurram, M.; Amin, M.U.; Haseeb, A.; Kakar, M. Berberine nanoparticles with enhanced in vitro bioavailability: Characterization and antimicrobial activity. Drug Des. Dev. Ther. 2018, 12, 303-312. [CrossRef]

225. Baldim, I.; Oliveira, W.P.; Kadian, V.; Rao, R.; Yadav, N.; Mahant, S.; Lucarini, M.; Durazzo, A.; Da Ana, R.; Capasso, R.; et al. Natural ergot alkaloids in ocular pharmacotherapy: Known molecules for novel nanoparticle-based delivery systems. Biomolecules 2020, 10, 980. [CrossRef]

226. Wu, Z.; Wang, Y.; Chen, L. Network-based drug repositioning. Mol. BioSyst. 2013, 9, 1268-1281. [CrossRef]

227. Baker, N.C.; Ekins, S.; Williams, A.J.; Tropsha, A. A bibliometric review of drug repurposing. Drug Discov. Today 2018, 23, 661-672. [CrossRef]

228. Portincasa, P. Colchicine, biologic agents and more for the treatment of Familial Mediterranean Fever. The Old, the New, and the Rare. Curr. Med. Chem. 2015, 23, 60-86. [CrossRef] [PubMed]

229. Panic, G.; Duthaler, U.; Speich, B.; Keiser, J. Repurposing drugs for the treatment and control of helminth infections. Int. J. Parasitol. Drugs Drug Resist. 2014, 4, 185-200. [CrossRef]

230. Turner, N.; Zeng, X.-Y.; Osborne, B.; Rogers, S.; Ye, J.-M. Repurposing drugs to target the diabetes epidemic. Trends Pharmacol. Sci. 2016, 37, 379-389. [CrossRef] [PubMed]

231. Lee, C.; Bhakta, S. The prospect of repurposing immunomodulatory drugs for adjunctive chemotherapy against tuberculosis: A critical review. Antibiotics 2021, 10, 91. [CrossRef] [PubMed]

232. Abdelaleem, M.; Ezzat, H.; Osama, M.; Megahed, A.; Alaa, W.; Gaber, A.; Shafei, A.; Refaat, A. Prospects for repurposing CNS drugs for cancer treatment. Oncol. Rev. 2019, 13, 411. [CrossRef] [PubMed]

233. Bayazeid, O.; Yalçın, F.N. Biological targets of 92 alkaloids isolated from Papaver genus: A perspective based on in silico pre-dictions. Med. Chem. Res. 2021, 30, 574-585. [CrossRef]

234. Gu, J.; Gui, Y.; Chen, L.; Yuan, G.; Lu, H.-Z.; Xu, X. Use of natural products as chemical library for drug discovery and network pharmacology. PLoS ONE 2013, 8, e62839. [CrossRef]

235. Schlesinger, N.; Firestein, B.L.; Brunetti, L. Colchicine in COVID-19: An old drug, new use. Curr. Pharmacol. Rep. 2020, 6, 137-145. [CrossRef]

236. Cusinato, J.; Cau, Y.; Calvani, A.M.; Mori, M. Repurposing drugs for the management of COVID-19. Expert Opin. Ther. Patents 2021, 31, 295-307. [CrossRef]

237. Levin, J.M.; Oprea, T.I.; Davidovich, S.; Clozel, T.; Overington, J.P.; Vanhaelen, Q.; Cantor, C.R.; Bischof, E.; Zhavoronkov, A. Artificial intelligence, drug repurposing and peer review. Nat. Biotechnol. 2020, 38, 1127-1131. [CrossRef] [PubMed]

238. Borquaye, L.S.; Gasu, E.N.; Ampomah, G.B.; Kyei, L.K.; Amarh, M.A.; Mensah, N.K.; Nartey, D. Alkaloids from Cryptolepis sanguinolenta as potential inhibitors of SARS-CoV-2 viral proteins: An in silico study. BioMed Res. Int. 2020, 2020, 5324560. [CrossRef]

239. Ghosh, R.; Chakraborty, A.; Biswas, A.; Chowdhuri, S. Identification of alkaloids from Justicia adhatoda as potent SARS CoV-2 main protease inhibitors: An in silico perspective. J. Mol. Struct. 2021, 1229, 129489. [CrossRef]

240. Garg, S.; Roy, A. In silico analysis of selected alkaloids against main protease (Mpro) of SARS-CoV-2. Chem. Biol. Interact. 2020, 332, 109309. [CrossRef]

241. Fournet, A.; Gantier, J.-C.; Gautheret, A.; Leysalles, L.; Munos, M.H.; Mayrargue, J.; Moskowitz, H.; Cavé, A.; Hocquemiller, R. The activity of 2-substituted quinoline alkaloids in BALB/c mice infected with Leishmania donovani. J. Antimicrob. Chemother. 1994, 33, 537-544. [CrossRef]

242. Fournet, A.; Ferreira, M.E.; de Arias, A.R.; Ortiz, S.T.; Fuentes, S.; Nakayama, H.; Schinini, A.; Hocquemiller, R. In vivo efficacy of oral and intralesional administration of 2-substituted quinolines in experimental treatment of new world cutaneous leishmaniasis caused by Leishmania amazonensis. Antimicrob. Agents Chemother. 1996, 40, 2447-2451. [CrossRef]

243. Muhammad, I.; Dunbar, D.C.; Khan, S.I.; Tekwani, B.L.; Bedir, E.; Takamatsu, S.; Ferreira, D.; Walker, L.A. Antiparasitic alkaloids from Psychotria klugii. J. Nat. Prod. 2003, 66, 962-967. [CrossRef] [PubMed]

244. Nakao, Y.; Shiroiwa, T.; Murayama, S.; Matsunaga, S.; Goto, Y.; Matsumoto, Y.; Fusetani, N. Identification of renieramycin a as an antileishmanial substance in a marine sponge Neopetrosia sp. Mar. Drugs 2004, 2, 55-62. [CrossRef]

245. Cordell, G.A.; Angerhofer, C.K.; Pezzuto, J.M. Recent studies on cytotoxic, anti-HIV and antimalarial agents from plants. Pure Appl. Chem. 1994, 66, 2283-2286. [CrossRef]

246. Hopkins, A.L. Network pharmacology. Nat. Biotechnol. 2007, 25, 1110-1111. [CrossRef]

247. Hopkins, A.L. Network pharmacology: The next paradigm in drug discovery. Nat. Chem. Biol. 2008, 4, 682-690. [CrossRef]

248. Kibble, M.; Saarinen, N.; Tang, J.; Wennerberg, K.; Mäkelä, S.; Aittokallio, T. Network pharmacology applications to map the unexplored target space and therapeutic potential of natural products. Nat. Prod. Rep. 2015, 32, 1249-1266. [CrossRef]

249. Doroghazi, J.R.; Albright, J.C.; Goering, A.W.; Ju, K.-S.; Haines, R.R.; Tchalukov, K.A.; Labeda, D.P.; Kelleher, N.L.; Metcalf, W.W. A roadmap for natural product discovery based on large-scale genomics and metabolomics. Nat. Chem. Biol. 2014, 10, 963-968. [CrossRef]

250. Challis, G.L. Exploitation of the Streptomyces coelicolor A3(2) genome sequence for discovery of new natural products and biosynthetic pathways. J. Ind. Microbiol. Biotechnol. 2014, 41, 219-232. [CrossRef]

251. Nett, M.; Ikeda, H.; Moore, B.S. Genomic basis for natural product biosynthetic diversity in the actinomycetes. Nat. Prod. Rep. 2009, 26, 1362-1384. [CrossRef]

252. Donadio, S.; Monciardini, P.; Sosio, M. Polyketide synthases and nonribosomal peptide synthetases: The emerging view from bacterial genomics. Nat. Prod. Rep. 2007, 24, 1073-1109. [CrossRef] 
253. Letzel, A.-C.; Pidot, S.J.; Hertweck, C. A genomic approach to the cryptic secondary metabolome of the anaerobic world. Nat. Prod. Rep. 2013, 30, 392-428. [CrossRef]

254. Calteau, A.; Fewer, D.P.; Latifi, A.; Coursin, T.; Laurent, T.; Jokela, J.; Kerfeld, C.A.; Sivonen, K.; Piel, J.; Gugger, M. Phylum-wide comparative genomics unravel the diversity of secondary metabolism in cyanobacteria. BMC Genom. 2014, 15, 977. [CrossRef]

255. Wilson, M.C.; Mori, T.; Rückert, C.; Uria, A.R.; Helf, M.J.; Takada, K.; Gernert, C.; Steffens, U.A.E.; Heycke, N.; Schmitt, S.; et al. An environmental bacterial taxon with a large and distinct metabolic repertoire. Nat. Cell Biol. 2014, 506, 58-62. [CrossRef]

256. Keller, N.P.; Turner, G.; Bennett, J.W. Fungal secondary metabolism from biochemistry to genomics. Nat. Rev. Microbiol. 2005, 3, 937-947. [CrossRef]

257. Fischbach, M.A.; Walsh, C.T. Assembly-line enzymology for polyketide and nonribosomal peptide antibiotics: Logic, machinery, and mechanisms. Chem. Rev. 2006, 106, 3468-3496. [CrossRef]

258. Singh, M.; Chaudhary, S.; Sareen, D. Non-ribosomal peptide synthetases: Identifying the cryptic gene clusters and decoding the natural product. J. Biosci. 2017, 42, 175-187. [CrossRef]

259. Winter, J.M.; Behnken, S.; Hertweck, C. Genomics-inspired discovery of natural products. Curr. Opin. Chem. Biol. 2011, 15, 22-31. [CrossRef]

260. Rutledge, P.J.; Challis, G.L. Discovery of microbial natural products by activation of silent biosynthetic gene clusters. Nat. Rev. Microbiol. 2015, 13, 509-523. [CrossRef]

261. Blin, K.; Andreu, V.P.; de los Santos, E.L.C.; Del Carratore, F.; Lee, S.Y.; Medema, M.H.; Weber, T. The antiSMASH database version 2: A comprehensive resource on secondary metabolite biosynthetic gene clusters. Nucl. Acids Res. 2019, 47, D625-D630.

262. Flissi, A.; Ricart, E.; Campart, C.; Chevalier, M.; Dufresne, Y.; Michalik, J.; Flahaut, C.; Lisacek, F.; Leclère, V.; Pupin, M. Norine: Update of the nonribosomal peptide resource. Nucl. Acids Res. 2020, 48, D465-D469.

263. Zierep, P.F.; Ceci, A.T.; Dobrusin, I.; Rockwell-Kollmann, S.C.; Günther, S. SeMPI 2.0—A web server for PKS and NRPS predictions combined with metabolite screening in natural product databases. Metabolites 2021, 11, 13.

264. Ugai, T.; Minami, A.; Gomi, K.; Oikawa, H. Genome mining approach for harnessing the cryptic gene cluster in Alternaria solani: Production of PKS-NRPS hybrid metabolite, didymellamide B. Tetrahedron Lett. 2016, 57, 2793-2796.

265. Chen, R.; Zhang, Q.; Tan, B.; Zheng, L.; Li, H.; Zhu, Y.; Zhang, C. Genome mining and activation of a silent PKS/NRPS gene cluster direct the production of totopotensamides. Org. Lett. 2017, 19, 5697-5700.

266. Tang, S.; Zhang, W.; Li, Z.; Li, H.; Geng, C.; Huang, X.; Lu, X. Discovery and characterization of a PKS-NRPS hybrid in Aspergillus terreus by genome mining. J. Nat. Prod. 2020, 83, 473-480.

267. Suroto, D.A.; Kitani, S.; Arai, M.; Ikeda, H.; Nihira, T. Characterization of the biosynthetic gene cluster for cryptic phthoxazolin A in Streptomyces avermitilis. PLoS ONE 2018, 13, e0190973.

268. Niehs, S.P.; Dose, B.; Scherlach, K.; Pidot, S.J.; Stinear, T.P.; Hertweck, C. Genome mining reveals endopyrroles from a nonribosomal peptide assembly line triggered in fungal-bacterial symbiosis. ACS Chem. Biol. 2019, 14, 1811-1818. [CrossRef]

269. Chiang, Y.-M.; Lee, K.-H.; Sanchez, J.F.; Keller, N.P.; Wang, C.C.C. Unlocking fungal cryptic natural products. Nat. Prod. Commun. 2009, 4, 1505-1510.

270. Zerikly, M.; Challis, G.L. Strategies for the discovery of new natural products by genome mining. ChemBioChem 2009, 10, 625-633. [CrossRef]

271. Weber, T.; Charusanti, P.; Musiol-Kroll, E.M.; Jiang, X.; Tong, Y.; Kim, H.U.; Lee, S.Y. Metabolic engineering of antibiotic factories: New tools for antibiotic production in actinomycetes. Trends Biotechnol. 2015, 33, 15-26. [CrossRef]

272. Wang, X.; Zhou, H.; Chen, H.; Jing, X.; Zheng, W.; Li, R.; Sun, T.; Liu, J.; Fu, J.; Huo, L. Discovery of recombinases enables genome mining of cryptic biosynthetic gene clusters in Burkholderiales species. Proc. Natl. Acad. Sci. USA 2018, 115, E4255-E4263.

273. Zheng, W.; Wang, X.; Zhou, H.; Zhang, Y.; Li, A.; Bian, X. Establishment of recombineering genome editing system in Paraburkholderia megapolitana empowers activation of silent biosynthetic gene clusters. Microb. Biotechnol. 2020, 13, 397-405. [CrossRef] [PubMed]

274. Prihoda, D.; Maritz, J.M.; Klempir, O.; Dzamba, D.; Woelk, C.H.; Hazuda, D.J.; Bitton, D.A.; Hannigan, G.D. The application potential of machine learning and genomics for understanding natural product diversity, chemistry, and therapeutic translatability. Nat. Prod. Rep. 2021. [CrossRef] [PubMed]

275. Clardy, J.; Walsh, C.J. Lessons from natural molecules. Nature 2004, 432, 829-837. [CrossRef]

276. Lorenz, P.; Eck, J. Metagenomics and industrial applications. Nat. Rev. Microbiol. 2005, 3, 510-516. [CrossRef]

277. Lefevre, F.; Robe, P.; Jarrin, C.; Ginolhac, A.; Zago, C.; Auriol, D.; Vogel, T.M.; Simonet, P.; Nalin, R. Drugs from hidden bugs: Their discovery via untapped resources. Res. Microbiol. 2008, 159, 153-161. [CrossRef]

278. Simon, C.; Daniel, R. Achievements and new knowledge unraveled by metagenomic approaches. Appl. Microbiol. Biotechnol. 2009, 85, 265-276. [CrossRef]

279. Riesenfeld, C.S.; Schloss, P.D.; Handelsman, J. Metagenomics: Genomic analysis of microbial communities. Annu. Rev. Genet. 2004, 38, 525-552. [CrossRef]

280. Frias-Lopez, J.; Shi, Y.; Tyson, G.W.; Coleman, M.L.; Schuster, S.C.; Chisholm, S.W.; DeLong, E.F. Microbial community gene expression in ocean surface waters. Proc. Natl. Acad. Sci. USA 2008, 105, 3805-3810. [CrossRef]

281. Banik, J.J.; Brady, S.F. Cloning and characterization of new glycopeptide gene clusters found in an environmental DNA megalibrary. Proc. Natl. Acad. Sci. USA 2008, 105, 17273-17277. [CrossRef] 
282. Donia, M.S.; Ruffner, D.E.; Cao, S.; Schmidt, E.W. Accessing the hidden majority of marine natural products through metagenomics. ChemBioChem 2011, 12, 1230-1236. [CrossRef]

283. Trindade, M.; van Zyl, L.J.; Navarro-Fernández, J.; Elrazak, A.A. Targeted metagenomics as a tool to tap into marine natural product diversity for the discovery and production of drug candidates. Front. Microbiol. 2015, 6, 890.

284. Mahapatra, G.P.; Raman, S.; Nayak, S.; Gouda, S.; Das, G.; Patra, J.K. Metagenomics approaches in discovery and development of new bioactive compounds from marine actinomycetes. Curr. Microbiol. 2019, 77, 645-656.

285. Carayannis, E.G.; Campbell, D.F.J. "Mode 3" and "Quadruple Helix": Toward a 21st century fractal innovation ecosystem. Int. J. Technol. Manag. 2009, 46, 201-234. [CrossRef]

286. Carayannis, E.G.; Barth, T.D.; Campbell, D.F.J. The Quintuple Helix innovation model: Global warming as a challenge and a driver for innovation. J. Innov. Entrep. 2012, 1, 2. [CrossRef]

287. Martins, V.W.B.; Rampasso, I.S.; Anholon, R.; Quelhas, O.L.G.; Filho, W. Knowledge management in the context of sustainability: Literature review and opportunities for future research. J. Clean. Prod. 2019, 229, 489-500. [CrossRef]

288. Cordell, G.A. Cyberecoethnopharmacolomics. J. Ethnopharmacol. 2019, 244, 112134. [CrossRef]

289. Ou-Yang, S.-S.; Lu, J.-Y.; Kong, X.-Q.; Liang, Z.-J.; Luo, C.; Jiang, H. Computational drug discovery. Acta Pharmacol. Sin. 2012, 33, 1131-1140.

290. Smith, J.S.; Roitberg, A.E.; Isayev, O. Transforming computational drug discovery with machine learning and AI. ACS Med. Chem. Lett. 2018, 9, 1065-1069. [CrossRef]

291. Schneider, G. Automating drug discovery. Nat. Rev. Drug Discov. 2018, 17, 97. [CrossRef]

292. Chen, H.; Kogej, T.; Engkvist, O. Cheminformatics in drug discovery, an industrial perspective. Mol. Inform. 2018, $37,1800041$.

293. Chan, H.C.S.; Shan, H.; Dahoun, T.; Vogel, H.; Yuan, S. Advancing drug discovery via artificial intelligence. Trends Pharmacol. Sci. 2019, 40, 592-604.

294. Schneider, P.; Walters, W.P.; Plowright, A.T.; Sieroka, N.; Listgarten, J.; Goodnow, R.A.; Fisher, J.; Jansen, J.M.; Duca, J.S.; Rush, T.S.; et al. Rethinking drug design in the artificial intelligence era. Nat. Rev. Drug Discov. 2020, 19, 353-364.

295. Zhao, L.; Ciallella, H.L.; Aleksunes, L.M.; Zhu, H. Advancing computer-aided drug discovery (CADD) by big data and data-driven machine learning modeling. Drug Discov. Today 2020, 25, 1624-1638.

296. MacConnell, A.B.; Price, A.K.; Paegel, B.M. An integrated microfluidic processor for DNA-encoded combinatorial library functional screening. ACS Comb. Sci. 2017, 19, 181-192. [CrossRef]

297. Baranczak, A.; Tu, N.P.; Marjanovic, J.; Searle, P.A.; Vasudevan, A.; Djuric, S.W. Integrated platform for expedited synthesispurification-testing of small molecule libraries. ACS Med. Chem. Lett. 2017, 8, 461-465. [CrossRef]

298. Clark, A.J.; Negron, C.; Hauser, K.; Sun, M.; Wang, L.; Abel, R.; Friesner, R.A. Relative binding affinity prediction of chargechanging sequence mutations with FEP in protein-protein interfaces. J. Mol. Biol. 2019, 431, 1481-1493. [CrossRef]

299. Capel, A.J.; Rimington, R.P.; Lewis, M.P.; Christie, S.D.R. 3D Printing for chemical, pharmaceutical and biological applications. Nat. Rev. Chem. 2018, 2, 422-436. [CrossRef]

300. Hartings, M.R.; Ahmed, Z. Chemistry from 3D printed objects. Nat. Rev. Chem. 2019, 3, 305-314. [CrossRef]

301. Sparkes, A.; Aubrey, W.; Byrne, E.; Clare, A.; Khan, M.N.; Liakata, M.; Markham, M.; Rowland, J.; Soldatova, L.N.; Whelan, K.E.; et al. Towards robot scientists for autonomous scientific discovery. Autom. Exp. 2010, 2, 1-11.

302. Lehár, J.; Krueger, A.S.; Avery, W.; Heilbut, A.M.; Johansen, L.M.; Price, E.R.; Rickles, R.J.; Short, G.F., III; Staunton, J.E.; Jin, X.; et al. Synergistic drug combinations tend to improve therapeutically relevant selectivity. Nat. Biotechnol. 2009, 27, 659-666. [CrossRef] [PubMed]

303. Kola, I.; Landis, J. Can the pharmaceutical industry reduce attrition rates? Nat. Rev. Drug Discov. 2004, 3, 711-716.

304. Lamb, J.; Crawford, E.D.; Peck, D.; Modell, J.W.; Blat, I.C.; Wrobel, M.J.; Lerner, J.; Brunet, J.P.; Subramanian, A.; Ross, K.N.; et al. The Connectivity Map: Using gene-expression signatures to connect small molecules, genes, and disease. Science 2006, 313, 1929-1935.

305. Wu, M.; Ma, C.; Wu, Y.; Li, S. Simultaneous LC analysis of five bioactive alkaloids in an anti-angiogenesis herbal formula, Qing-Luo-Yin. Chromatographia 2008, 68, 579-585. [CrossRef]

306. Li, S.; Zhang, B.; Zhang, N. Network target for screening synergistic drug combinations with application to traditional Chinese medicine. BMC Syst. Biol. 2011, 5, S10. [CrossRef]

307. Libbrecht, M.W.; Noble, W.S. Machine learning applications in genetics and genomics. Nat. Rev. Genet. 2015, 16, 321-332. [CrossRef]

308. Tarca, A.L.; Carey, V.J.; Chen, X.-w.; Romero, R.; Drăghici, S. Machine learning and its applications to biology. PLoS Comput. Biol. 2007, 3, e116. [CrossRef]

309. Chen, H.; Engkvist, O.; Wang, Y.; Olivecrona, M.; Blaschke, T. The rise of deep learning in drug discovery. Drug Discov. Today 2018, 23, 1241-1250.

310. Lo, Y.-C.; Rensi, S.E.; Torng, W.; Altman, R.B. Machine learning in chemoinformatics and drug discovery. Drug Discov. Today 2018, $23,1538-1546$.

311. Stephenson, N.; Shane, E.; Chase, J.; Rowland, J.; Ries, D.; Justice, N.; Zhang, J.; Chan, L.; Cao, R. Survey of machine learning techniques in drug discovery. Curr. Drug Metab. 2019, 20, 185-193. [CrossRef]

312. Gini, G.; Zanoli, F.; Gamba, A.; Raitano, G.; Benfenati, E. Could deep learning in neural networks improve the QSAR models? SAR QSAR Environ. Res. 2019, 30, 617-642. [CrossRef] 
313. Hu, S.; Chen, P.; Gu, P.; Wang, B. A deep learning-based chemical system for QSAR prediction. IEEE J. Biomed. Health Inform. 2020, 24, 3020-3028.

314. Aliper, A.; Plis, S.; Artemov, A.; Ulloa, A.; Mamoshina, P.; Zhavoronkov, A. Deep learning applications for predicting pharmacological properties of drugs and drug repurposing using transcriptomic data. Mol. Pharm. 2016, 13, 2524-2530. [CrossRef]

315. Wu, K.; Zhao, Z.; Wang, R.; Wei, G.-W. TopP-S: Persistent homology-based multi-task deep neural networks for simultaneous predictions of partition coefficient and aqueous solubility. J. Comput. Chem. 2018, 39, 1444-1454. [CrossRef]

316. Stokes, J.M.; Yang, K.; Swanson, K.; Jin, W.; Cubillos-Ruiz, A.; Donghia, N.N.; MacNair, C.R.; French, S.; Carfrae, L.A.; BloomAckermann, Z.; et al. A deep learning approach to antibiotic discovery. Cell 2020, 180, 688-702. [CrossRef]

317. Ekins, S.; Siqueira-Neto, J.L.; McCall, L.-I.; Sarker, M.; Yadav, M.; Ponder, E.L.; Kallel, E.A.; Kellar, D.; Chen, S.; Arkin, M.; et al Machine learning models and pathway genome data base for Trypanosoma cruzi drug discovery. PLoS Negl. Trop. Dis. 2015, 9 , e0003878.

318. Egieyeh, S.; Syce, J.; Malan, S.F.; Christoffels, A. Predictive classifier models built from natural products with antimalarial bioactivity using machine learning approach. PLoS ONE 2018, 13, e0204644. [CrossRef] [PubMed]

319. Chen, Y.; Stork, C.; Hirte, S.; Kirchmair, J. NP-Scout: Machine learning approach for the quantification and visualization of the natural product-likeness of small molecules. Biomolecules 2019, 9, 43.

320. Grisoni, F.; Merk, D.; Friedrich, L.; Schneider, G. Design of natural-product-inspired multitarget ligands by machine learning. ChemMedChem 2019, 14, 1129-1134. [CrossRef] [PubMed]

321. Rodrigues, T.; Bernardes, G.J.L. Machine learning for target discovery in drug development. Curr. Opin. Chem. Biol. 2020, 56, 16-22. [CrossRef]

322. Capecchi, A.; Reymond, J.-L. Assigning the origin of microbial natural products by chemical space map and machine learning. Biomolecules 2020, 10, 1385. [CrossRef] [PubMed]

323. Ekins, S.; Puhl, A.C.; Zorn, K.M.; Lane, T.R.; Russo, D.P.; Klein, J.J.; Hickey, A.J.; Clark, A.M. Exploiting machine learning for end-to-end drug discovery and development. Nat. Mat. 2019, 18, 435-441. [CrossRef] [PubMed]

324. Zhavoronkov, A. Artificial intelligence for drug discovery, biomarker development, and generation of novel chemistry. Mol. Pharm. 2018, 15, 4311-4313. [CrossRef]

325. Vamathevan, J.; Clark, D.; Czodrowski, P.; Dunham, I.; Ferran, E.; Lee, G.; Li, B.; Madabhushi, A.; Shah, P.; Spitzer, M.; et al. Applications of machine learning in drug discovery and development. Nat. Rev. Drug Discov. 2019, 18, 463-477. [CrossRef]

326. Davies, D.W.; Butler, K.T.; Isayev, O.; Walsh, A. Materials discovery by chemical analogy: Role of oxidation states in structure prediction. Faraday Discuss. 2018, 211, 553-568. [CrossRef]

327. Mayr, A.; Klambauer, G.; Unterthiner, T.; Steijaert, M.; Wegner, J.K.; Ceulemans, H.; Clevert, D.A.; Hochreiter, S. Large-scale comparison of machine learning methods for drug target prediction on ChEMBL. Chem. Sci. 2018, 9, 5441-5451.

328. Sorokina, M.; Steinbeck, C. Review on natural products databases: Where to find data in 2020. J. Cheminform. 2020, 12, 1-51. [CrossRef]

329. Allard, P.-M.; Bisson, J.; Azzollini, A.; Pauli, G.F.; Cordell, G.A.; Wolfender, J.-L. Pharmacognosy in the digital era: Shifting to contextualized metabolomics. Curr. Opin. Biotechnol. 2018, 54, 57-64. [CrossRef]

330. Zampieri, G.; Vijayakumar, S.; Yaneske, E.; Angione, C. Machine and deep learning meet genome-scale metabolic modeling. PLoS Comput. Biol. 2019, 15, e1007084. [CrossRef]

331. Wouters, O.J.; McKee, M.; Luyten, J. Estimated research and development investment needed to bring a new medicine to market, 2009-2018. J. Am. Med. Assoc. 2020, 323, 844-853. [CrossRef]

332. Henry, D.; Lexchin, J. The pharmaceutical industry as a medicines provider. Lancet 2002, 360, 1590-1595. [CrossRef] 